\title{
Influence of strain rate and acceleration on the behaviour of reconstituted clays at small strains
}

\author{
K. K. SORENSEN*, B. A. BAUDET $\uparrow$ and B. SIMPSON
}

This paper attempts to bridge the gap between the wellknown characteristics of strain rate-independent elastic stiffness and of the time-dependent behaviour of clays at large strains. Effects of acceleration, strain rate and ageing are examined in the very small to small strain region, using results from tests on reconstituted London Clay and kaolin. Static measurements of the shear modulus at small strains, using local instrumentation, indicate that the shear modulus is rate-independent when the soil is subjected to elastic deformations only. Most often, in practice, soil specimens are left to rest between the compression and shearing stages, until deformations associated with creep become negligible. The testing strain rate imposed upon shearing induces a temporary acceleration of strains, which results in very high measured stiffnesses. Test data show, however, that when the shearing axial strain rate is of the same order of magnitude as that measured at the end of the compression/creep stage, the remaining plastic creep strains influence the measured stiffness, which is then measured to be comparatively low. Test data also seem to show that temporary strain acceleration may hide effects of recent stress path rotation. Additionally, bender element tests were performed during isotropic compression tests with changes in stress rate and creep stages. The data indicate that the strain rate affects the value of the dynamic shear modulus of the soil. It is suggested that the increase in dynamic shear modulus during short-term creep is caused by mechanisms linked to the gradual decrease in strain rate during creep, but further investigation would be needed to clarify which physical mechanisms. A new method to account for strain rate in evaluating the dynamic shear modulus of normally consolidated reconstituted clays is finally proposed.

KEYWORDS: clays; creep; dynamics; laboratory tests; stiffness; time dependence
La présente communication s'efforce d'établir un lien entre les propriétés bien connues de la rigidité élastique indépendante de la vitesse de déformation et le comportement temporel des argiles avec des déformations élevées. On examine les effets de l'accélération, de la vitesse de déformation et du vieillissent dans une plage allant des très petites aux petites déformations, en utilisant ensuite les résultats de tests sur de l'argile de Londres et du kaolin. Des mesures statiques du module de cisaillement avec de petites déformations, effectuées avec instrumentation locale, indiquent que le module de cisaillement est indépendant des déformations, lorsque le sol n'est soumis qu'à des déformations élastiques. Dans la pratique, on laisse reposer, dans la plupart des cas, les spécimens de sol entre les stades de la compression et du cisaillement, jusqu'à ce que les déformations correspondant au fluage deviennent négligeables. La vitesse de déformation d'essai, imposée par le cisaillement, induit une accélération temporaire des déformations, qui engendre des rigidités mesurées très élevées. Toutefois, les données d'essai indiquent que, lorsque l'ordre de magnitude de la vitesse de déformation axiale de cisaillement est le même que celui qui est mesuré à la fin du stade de compression /fluage, les déformations restantes de fluage plastique influent sur la rigidité mesurée, qui, lorsqu'on la mesure, s'avère relativement basse. En outre, les données d'essai semblent indiquer que l'accélération temporaire de la déformation pourrait masquer les effets d'une rotation récente du chemin de déformation. En outre, des tests aux bender elements ont été effectués au cours de tests de compression isotrope, avec des variations de la vitesse de contrainte et des stades de fluage. Les données indiquent que la vitesse de déformation affecte la valeur du module de cisaillement dynamique du sol. On estime que l'augmentation du module de cisaillement dynamique, lors du fluage de courte durée, est causée par des mécanismes liés à la diminution progressive de la vitesse de déformation au cours du fluage, mais de nouvelles recherches seront nécessaires pour clarifier de quels mécanismes physiques il s'agit. Enfin, une nouvelle méthode, permettant de tenir compte de la vitesse de déformation pour l'évaluation du module de cisaillement dynamique d'argiles reconstituées consolidées normalement, est proposée.

\section{INTRODUCTION}

Most geotechnical constructions are carried out in soils which have stood for long periods of rest before construc-

\footnotetext{
Manuscript received 30 August 2007; revised manuscript accepted 12 October 2009. Published online ahead of print 15 April 2010. Discussion on this paper closes on 1 March 2011, for further details see p. ii.

* Engineering College of Aarhus, Denmark; formerly University College London, UK.

† Department of Civil Engineering, University of Hong Kong; formerly University College London, UK.

+ Ove Arup and Partners Ltd, London, UK.
}

tion, which then proceeds in stages, with periods of construction alternating with periods of rest. Each stage is evidently accompanied by a change in the rate of soil straining in the ground, a fact that has been largely neglected in practice. Published laboratory test results have shown that strain rate and time effects, whether they are viscous effects (creep, stress relaxation, strain rate) or ageing effects (thixotropy, cementation), affect the stiffness, strength and size of the yield surface of a soil at large strains (e.g. Leroueil \& Marques, 1996; Soga \& Mitchell, 1996; Tatsuoka et al., 2002; Sorensen et al., 2007). The zone of linear elasticity, typically in the region of $0.001 \%$ for soft clays and one or two orders of magnitude higher for artificially cemented 
soils and soft rocks, has also been found to grow in size with ageing and strain rate (Jardine, 1992; Shibuya et al., 1996).

The maximum shear modulus of soils, which is thought to correspond to the elastic stiffness, can be obtained from either dynamic methods (e.g. bender elements or resonant column tests); it is then referred to as $G_{0}$. Alternatively, it can be determined from high-resolution local strain gauges able to measure very small $\left(<10^{-4 \%}\right)$ to small $(<0 \cdot 01 \%)$ strains; it is then referred to as $G_{\max }$, where $G$ is calculated using the triaxial deviator stress, $q$, and shear strain, $\varepsilon_{\mathrm{s}}$, as $G=\Delta q / 3 \Delta \varepsilon_{\text {s }}$. Some empirical expressions have been proposed for the elastic stiffness as a function of current stress and state, for example Simpson (1992) or Viggiani \& Atkinson (1995) (see equation (2) later). These expressions were determined from dynamic tests during monotonic loading carried out at constant stress or strain rate, assuming that the elastic stiffness is independent of strain rate. Test data from static small strain measurements during monotonic loading presented by Shibuya et al. (1996) for NSF-clay confirmed that for that clay the maximum Young's modulus $E_{\max }$ measured using high-resolution local transducers is constant for axial strain rates between $0.7 \% / \mathrm{h}$ and $84 \% / \mathrm{h}$. Reported data from bender element tests carried out during creep stages show, however, that in most cases $G_{0}$ increases with creep time in excess of what would be expected from the associated reduction in void ratio (e.g. Lo Presti et al., 1996; Shibuya, 2000; Lohani et al., 2001; Rammah et al., 2004). Anderson \& Stokoe (1978) suggested, based on data from tests on ball kaolinite, that the observed increase in the dynamic stiffness was primarily a result of the 'strengthening of physical bonds', and it was subsequently widely accepted that the increase in dynamic shear modulus during creep was due to 'structuration' arising from ageing effects.

Characteristics of strain-rate-independent stiffness, and the effects of strain rate and time on soil behaviour, are well documented, but no detailed study so far has been carried out on the effects of strain rate on the stiffness in the very small to small region. This paper examines the influence of change in strain rate and acceleration on the shear modulus, within and outside the elastic region. Bender element test data obtained during constant rate of stress isotropic compression and constant effective stress creep are used to show that the increase in dynamic shear modulus typically observed with time may be related to changes in strain rate during the creep period. A new method to account for strain rate in evaluating the dynamic shear modulus of normally consolidated reconstituted clays is finally proposed.

\section{TESTING MATERIALS AND SAMPLE PREPARATION}

Specimens of reconstituted London Clay and Speswhite kaolin were tested. Natural London Clay can be characterised as a very stiff and heavily overconsolidated fissured clay deposited under marine conditions in the Eocene period (de Freitas \& Mannion, 2007). The clay minerals present are illite, and to a lesser extent kaolinite and smectite. The undisturbed rotary core sample used in the study was retrieved from the ground investigation at Heathrow Airport Terminal 5 (T5), West London, as part of a wider study on London Clay (Gasparre et al., 2007a; 2007b; Hight et al., 2007). The sample studied corresponded to a depth of 13.95-15.45 m below ground level, corresponding to the top of the $\mathrm{B}_{2(\mathrm{~b})}$-sub-unit (Gasparre, 2005). Speswhite kaolin on the other hand is an inorganic, low-plasticity clay which is produced from weathered granite and is commercially available. It was chosen as it would be a good reference soil to study ageing characteristics: kaolinite particles, when tested in neutral $\mathrm{pH}$ pore water conditions, do not generally develop time-dependent bonding or cementation (G. Morris, 2003, personal communication). The geotechnical index properties of the two clays are listed in Table 1 .

The reconstituted specimens of London Clay were created by thoroughly mixing trimmings from the undisturbed rotary core with tap water until a homogenous paste was obtained at a water content of about 1.6 times the liquid limit. The paste was then pre-consolidated under a vertical effective stress of $90 \mathrm{kPa}$ in a tall Perspex floating ring consolidometer (inner diameter of $38 \mathrm{~mm}$ ) to make the specimen strong enough to handle. The kaolin specimens were created in a similar way by mixing kaolin powder and tap water until a smooth paste was formed at approximately $1 \cdot 3$ times the liquid limit. The kaolin paste was then pre-consolidated as before. After set-up in the triaxial cell all reconstituted specimens were saturated under a back pressure of $300 \mathrm{kPa}$ before being compressed isotropically.

\section{TESTING PROCEDURES \\ Testing apparatus}

The tests on reconstituted London Clay and kaolin were performed in a computer-controlled stress path triaxial apparatus (Bishop \& Wesley, 1975) with either stress- or straincontrolled loading. Local measurements of axial and radial strains were taken using miniature linear variable differential transformers (LVDTs) (Cuccovillo \& Coop, 1997) of resolution $0.0002 \%$ (strain) during the shearing stress probes, while miniature Hall effect transducers of resolution $0.005 \%$ (strain) (Clayton \& Khatrush, 1986) were used, in parallel with bender elements, during the isotropic compression tests. Three transducers were used on each specimen: two placed diametrically opposite along the vertical axis, with a third transducer held in a specially built radial belt to measure the radial strain. Pore water drainage was through the base, complemented by radial drains made of vertical strips of filter paper placed at equal intervals on the specimen's perimeter. The volume changes were measured using a $50 \mathrm{cc}$ Imperial College-type volume gauge fitted with a LVDT displacement transducer of resolution $0 \cdot 005 \%$ (strain).

Triaxial tests on reconstituted London Clay to investigate the influence of temporary strain acceleration/deceleration on the stress-strain response at small strains

Five drained triaxial shearing tests were carried out, with stress paths and resting periods between the tests as shown

Table 1. Geotechnical properties of tested materials

\begin{tabular}{l|c|c|c|c|c|c}
\hline Material & $w_{\mathrm{p}}: \%$ & $w_{\mathrm{L}}: \%$ & PI: \% & $G_{\mathrm{s}}: \mathrm{g} / \mathrm{cm}^{3}$ & CF: \% & $k: \mathrm{m} / \mathrm{s}$ \\
\hline Speswhite kaolin* & 35 & 65 & 30 & $2 \cdot 68$ & 100 & $\sim 10^{-10}-10^{-9 \dagger}$ \\
London Clay - B ${ }_{2(\mathrm{~b}) \text {-sub-unit }}^{*}$ & 28 & 65 & 37 & $2 \cdot 73$ & 54 & $\sim 10^{-11}-10^{-10}$ \\
\hline
\end{tabular}

* After Atkinson et al. (1987).

$\dagger$ After Al-Tabbaa \& Wood (1987).

After Gasparre (2005) - samples taken at the same site and sub-unit. 
in Fig. 1 and Table 2. Three tests were sheared in compression (LC2, LC3a,g) and two in extension (LC3e,f) from the isotropic stress state achieved at the end of compression (LC2, LC3a) or swelling (LC3e,f,g). The confining pressure and backpressure were kept constant during the stress probes. The specimens were left to rest before shearing for periods ranging from no time to eleven days. The axial strain rate was monitored during the compression/swelling and resting stages; the remaining strain rate after the end of compression/swelling and resting is referred to here as axial creep rate. Shearing was then applied using strain control. By varying the axial strain rate during shearing in a stepwise manner, from values of axial strain rates lower than the

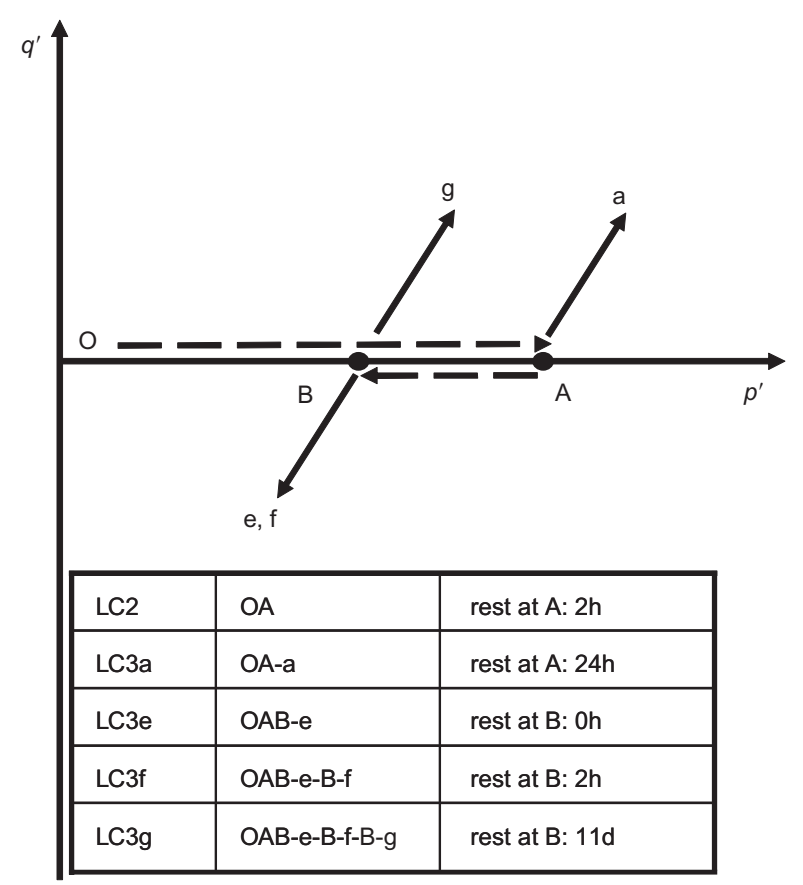

Fig. 1. Schematic diagram showing the stress paths followed during the various stress probes remaining axial creep strain rate (deceleration) to values higher than the axial creep strain rate (acceleration), the influence of temporary strain acceleration and deceleration on the stress-strain response could be observed. In each shearing test the testing axial strain rate was controlled by means of a stepping motor and varied between two to three different levels in the interval between $0.006 \% / \mathrm{h}$ and $0 \cdot 05 \% / \mathrm{h}$. The strain rate level was typically maintained for several hours, but it was changed more often (every 15-60 min) when investigating the behaviour within the elastic region. The values of strain rates were chosen to be sufficiently slow to give negligible build-up of excess pore water pressure during shearing. Since pore water pressures were not continuously monitored during the drained testing, several checks were performed by closing the drainage valve temporarily during testing in order to observe the build-up of excess pore water pressure. The checks verified an insignificant build-up of excess pore water pressure, being less than $2 \%$ of the current mean effective stress under the highest applied rate of axial strain of $0.05 \% / \mathrm{h}$.

In tests LC2 and LC3a, the specimens were isotropically normally consolidated at $p^{\prime}=300 \mathrm{kPa}$ at the start of shearing. Test LC3a being the first of a series of short drained probes on the same specimen, the stress state was brought back to the isotropic state $p^{\prime}=300 \mathrm{kPa}$ (drained triaxial extension path aA in Fig. 1) before isotropic swelling to $p^{\prime}=188 \mathrm{kPa}$ (path $\mathrm{AB}$ ). From $\mathrm{B}$, the specimen was subjected to two extension tests (LC3e and LC3f) and a compression test $(\mathrm{LC} 3 \mathrm{~g})$. The deviator stress $q$ was generally kept below $\pm 12 \mathrm{kPa}$ in the stress probes.

Isotropic compression tests on reconstituted London Clay and kaolin to investigate the influence of time and testing strain rate on the dynamic shear modulus

Isotropic compression tests were carried out on two specimens of reconstituted London Clay (LC-iso1 and LC-iso2) and one specimen of kaolin (K-iso). During the compression, step changes in the confining stress rate were made. Additionally, at different stages during the individual tests, prolonged periods of creep were introduced for up to one

Table 2. Details of stress probes on reconstituted London Clay

\begin{tabular}{|c|c|c|c|c|c|c|}
\hline & $\mathrm{LC} 1$ & $\mathrm{LC} 2$ & $\mathrm{LC} 3 \mathrm{a}$ & $\mathrm{LC} 3 \mathrm{e}$ & LC3f & $\mathrm{LC} 3 \mathrm{~g}$ \\
\hline $\begin{array}{l}\text { Isotropic compression/ } \\
\text { swelling }\end{array}$ & $\begin{array}{l}\text { Isotropic } \\
\text { compression to } \\
p^{\prime}=300 \mathrm{kPa}\end{array}$ & $\begin{array}{l}\text { Isotropic } \\
\text { compression to } \\
p^{\prime}=300 \mathrm{kPa}\end{array}$ & $\begin{array}{l}\text { Isotropic } \\
\text { compression to } \\
p^{\prime}=300 \mathrm{kPa}\end{array}$ & $\begin{array}{l}\text { Isotropic } \\
\text { compression } \\
\left(p^{\prime}=300 \mathrm{kPa}\right) \\
\text { then swelling (to } \\
\left.p^{\prime}=188 \mathrm{kPa}\right)\end{array}$ & $\begin{array}{l}\text { Isotropic } \\
\text { compression } \\
\left(p^{\prime}=300 \mathrm{kPa}\right) \\
\text { then swelling (to } \\
\left.p^{\prime}=188 \mathrm{kPa}\right)\end{array}$ & $\begin{array}{l}\text { Isotropic } \\
\text { compression } \\
\left(p^{\prime}=300 \mathrm{kPa}\right) \\
\text { then swelling (to } \\
\left.p^{\prime}=188 \mathrm{kPa}\right)\end{array}$ \\
\hline $\begin{array}{l}\text { Rest period at end of } \\
\text { compression }\end{array}$ & 7 hours & 2 hours & 24 hours & 0 hour & 2 hours & 11 days \\
\hline $\begin{array}{l}\text { Axial total stress rate used } \\
\text { during compression/ } \\
\text { swelling (corresponding } \\
\text { axial strain rate) }\end{array}$ & $\begin{array}{l}3 \mathrm{kPa} / \mathrm{h} \\
(0 \cdot 07 \% / \mathrm{h})\end{array}$ & $\begin{array}{l}3 \mathrm{kPa} / \mathrm{h} \\
(0 \cdot 07 \% / \mathrm{h})\end{array}$ & $\begin{array}{l}3 \mathrm{kPa} / \mathrm{h} \\
(0 \cdot 07 \% / \mathrm{h})\end{array}$ & $\begin{array}{l} \pm 3 \mathrm{kPa} / \mathrm{h} \\
( \pm 0 \cdot 07 \% / \mathrm{h})\end{array}$ & $\begin{array}{l} \pm 3 \mathrm{kPa} / \mathrm{h} \\
( \pm 0 \cdot 07 \% / \mathrm{h})\end{array}$ & $\begin{array}{l} \pm 3 \mathrm{kPa} / \mathrm{h} \\
( \pm 0 \cdot 07 \% / \mathrm{h})\end{array}$ \\
\hline $\begin{array}{l}\text { Axial strain rate }{ }^{*} \text { at end } \\
\text { of rest period: } \% / \mathrm{h}\end{array}$ & $0 \cdot 04$ & $0 \cdot 016$ & $0 \cdot 0015$ & -0.006 & $-0 \cdot 0003$ & $0 \cdot 0002$ \\
\hline Shearing & $\begin{array}{l}\text { Drained } \\
\text { compression }\end{array}$ & $\begin{array}{l}\text { Drained } \\
\text { compression }\end{array}$ & $\begin{array}{l}\text { Drained } \\
\text { compression }\end{array}$ & $\begin{array}{l}\text { Drained } \\
\text { extension }\end{array}$ & $\begin{array}{l}\text { Drained } \\
\text { extension }\end{array}$ & $\begin{array}{l}\text { Drained } \\
\text { compression }\end{array}$ \\
\hline Stress path rotation & $72^{\circ}$ & $72^{\circ}$ & $72^{\circ}$ & $72^{\circ}$ & $180^{\circ}$ & $0^{\circ}$ \\
\hline $\begin{array}{l}\text { Testing axial strain rate }{ }^{\dagger} \\
\text { used at start of shearing: } \\
\% / \mathrm{h}\end{array}$ & 0.006 & $0 \cdot 016$ & $0 \cdot 006$ & -0.006 & $-0 \cdot 006$ & $0 \cdot 015$ \\
\hline $\begin{array}{l}\text { Measured value of } G^{\prime} / p^{\prime} \\
\text { at start of shearing }\end{array}$ & - & 60 & 215 & 95 & 180 & 315 \\
\hline
\end{tabular}

* Measured using LVDTs.

$\dagger$ Controlled by a stepper motor. 
month. Changes in volume were measured using the external volume gauge as well as the local LVDTs. During all stages the vertical dynamic shear modulus was determined from bender element tests carried out at suitable intervals.

The dynamic shear modulus $G_{0}$ can be related to the velocity of the propagating shear wave, $V_{\mathrm{S}}$, by the following simple relationship

$$
G_{0}=\rho V_{\mathrm{S}}^{2}=\rho\left(\frac{L}{T}\right)^{2}
$$

where $L$ is the tip-to-tip travel distance, $T$ is the travel time and $\rho$ is the bulk density of the soil. The three different methods typically used to determine the travel time were compared; these are

(a) the first arrival method in time domain, for example Abbiss (1981), Viggiani \& Atkinson (1995)

(b) the method using characteristic points, for example Jovicic et al. (1996)

(c) the phase-delay method in the frequency domain, for example Viggiani \& Atkinson (1995), Greening et al. (2003).

The frequency of the transmitted signal - here a multiple pulse or continuous sine wave - was found to have a significant influence on the amplitude and wave-form of the received signal. Generally, for a given state, the combination of the specimen and bender element was found to resonate at a specific frequency, referred to as 'dominant resonant frequency', at which the amplitude of the received signal reached a maximum. The resonant frequency was found to vary between specimens of kaolin and London Clay and was also found to increase with increasing confining stress (4$32 \mathrm{kHz}$ in test $\mathrm{K}$-iso, $3-9 \mathrm{kHz}$ in test LC-iso $1,3-6 \mathrm{kHz}$ in test $\mathrm{LC}$-iso2).

Method (a) was found difficult to use in tests where nearfield effects and noise are significant, but yielded consistent results at values of frequency higher than the dominant resonant frequency. Method $(b)$ is only reliable if the sent and received signals have the same shape, which was usually achieved when the dominant resonant frequency of the specimen-bender element system was used. The peaks or troughs from a continuous sine wave or a multiple pulse signal (at least four pulses) were found to be the most reliable to use as characteristic points. In method $(c)$, the automatic computerised spectrum analyser 'Abets' (Greening et al., 2003) was used to obtain the complete diagram of relative phase against frequency from a transmitted frequency sweep signal (bandwidth of $1-50 \mathrm{kHz}$ ). It was found that the gradient of the complete phase-diagram from Abets, which is equal to the travel time, varies significantly with frequency and hence a certain degree of subjectivity was applied when choosing a suitable interval for determining the travel time. Generally, the phase-delay method appeared to overestimate the travel time compared to the time obtained from the first arrival method or peak-to-peak correlation method, by less at frequencies around the dominant resonant frequency (see Fig. 2). In this study, the method of correlation between characteristic peaks or troughs, at the dominant resonant frequency and using a continuous sine wave was thus deemed the most suitable because of the consistent results it yielded, and also because of its reliability and simplicity. The chosen method of correlation was periodically checked against the other methods mentioned above.

The stress rates used on the normal compression line (NCL) were $0.3 \mathrm{kPa} / \mathrm{h}$ and $3 \mathrm{kPa} / \mathrm{h}$ in tests on reconstituted London Clay, and $0 \cdot 1 \mathrm{kPa} / \mathrm{h}, 1 \mathrm{kPa} / \mathrm{h}$ and $5 \mathrm{kPa} / \mathrm{h}$ in the test on kaolin. During the isotropic compression on London Clay,

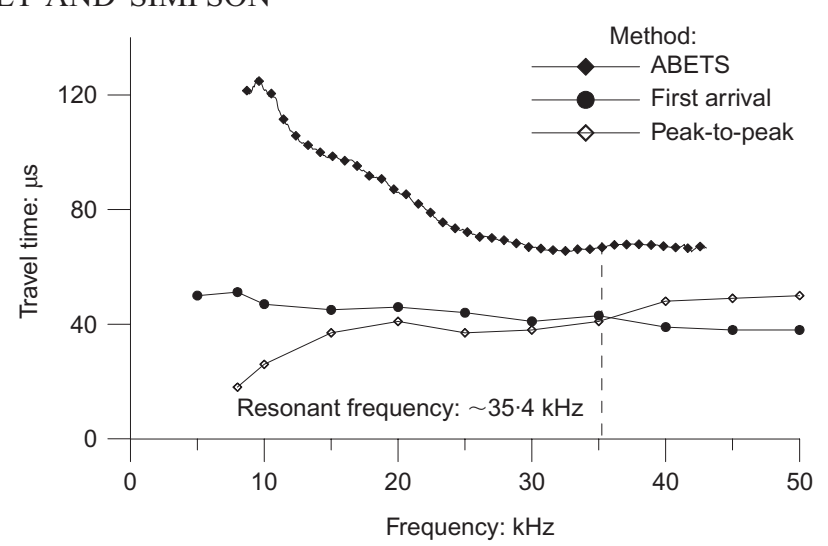

Fig. 2. Comparison between travel times obtained from different methods

the drainage valve was temporarily closed at given stress levels, in order to monitor the potential build-up of excess pore water pressure. The maximum ratio of excess pore water pressure to mean total stress was found to be, at the highest stress rate of $3 \mathrm{kPa} / \mathrm{h}$, equal to about $7 \%$ when the mean effective stress $p^{\prime}=80 \mathrm{kPa}$. It was measured again just after decreasing the strain rate to $0.3 \mathrm{kPa} / \mathrm{h}$, at a mean effective stress $p^{\prime}=91 \mathrm{kPa}$, to be only about $3 \%$. It was generally found that the excess pore water pressure reduced with increasing stress, for example at $96 \mathrm{kPa}$, at the lowest $0.3 \mathrm{kPa} / \mathrm{h}$ rate, the ratio to the mean total stress was less than $1 \%$. The test data presented later show that the shift in NCL when changing strain rate is larger than what would be calculated by taking account of the pore water pressure measured and reported above. Kaolin having a value of permeability one to two orders of magnitude higher than London Clay (see Table 1), it was assumed that during test $\mathrm{K}$-iso the build-up of excess pore water pressure would be small enough to have drained conditions, even under the highest applied stress rate of $5 \mathrm{kPa} / \mathrm{h}$. The control of stress rate rather than strain rate resulted in slight variations in the strain rates during stages of otherwise constant strain rate over most of the tested stress range, although larger variations are generally seen towards the end of the tests at higher stress levels (see Fig. 3). This however appears not to have affected the results significantly, as seen from the data presented in the following sections.

\section{EFFECT OF STRAIN RATE HISTORY AND STRESS PATH} HISTORY ON THE STIFFNESS AT SMALL STRAINS

Figure 4 shows a simple illustration of how acceleration and deceleration can influence a soil's response at small

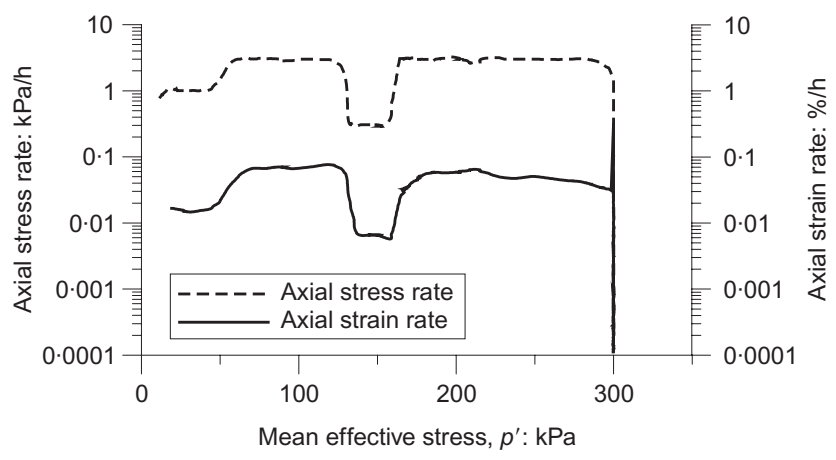

Fig. 3. Local axial strain rates measured during the isotropic compression LC-iso1 performed at constant rates of stress ( 3 and $0.3 \mathrm{kPa} / \mathrm{h}$ ) on normally consolidated reconstituted London Clay. 


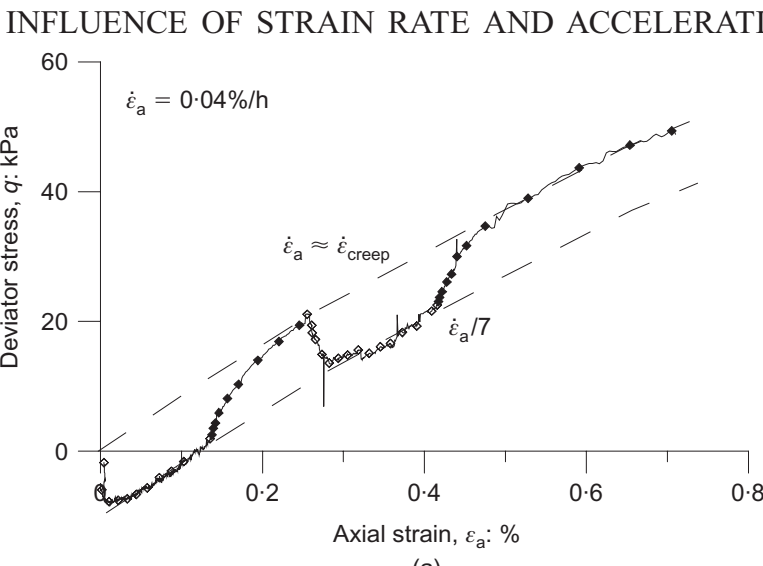

(a)

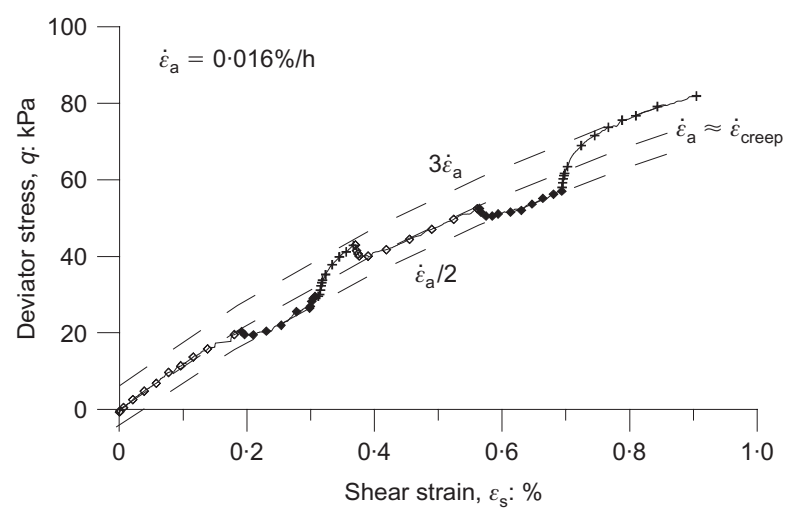

(b)

Fig. 4. Typical response of an isotropically normally consolidated reconstituted sample of London Clay $\left(p_{0}^{\prime}=300 \mathrm{kPa}\right)$ during drained shearing with step-wise changes in axial strain rate: (a) test $\mathrm{LC1}$, initial testing axial strain rate lower than measured axial creep rate; (b) test LC2, initial testing axial strain rate equal to measured axial creep rate. Different symbols are used for different strain rates

strains. The stress-strain curves were obtained from tests on reconstituted specimens of London Clay (LC1 and LC2) that were compressed isotropically to $300 \mathrm{kPa}$ before shearing drained with varying axial strain rates. Each specimen was left to rest for a short period of time before starting shearing, during which the axial creep rate was monitored. In Fig. 4(a), data are shown for a specimen which was sheared using an initial axial strain rate lower than the axial creep rate, while in Fig. 4(b), the data are for a specimen which was initially sheared with an axial strain rate equal to the axial creep rate. The results show that the decrease in axial strain rate caused a stiff response with a reversal in stress path, but when the axial strain rate was chosen to be equal to the axial creep rate there was no marked change in the curvature of the stress-strain curve.

Creep strains can overshadow the real behaviour of a soil and it is current practice to let specimens of soil rest between the compression stage and shearing stage of a test until the rate of deformation due to creep becomes negligible (Jardine, 1994; Clayton \& Heymann, 2001). As a result, when the shearing stage is started at a given axial strain rate, that axial strain rate is necessarily higher than the creep axial strain rate and the soil experiences an acceleration of both axial and shear strains. It may therefore be that the maximum value of stiffness $G_{\max }$ typically measured from local gauges to characterise soil behaviour at small strains is a result of the combined effects of the testing procedure and the true soil behaviour.

Figures 5-7 show data from tests designed to understand the interaction between stress path and strain rate history,

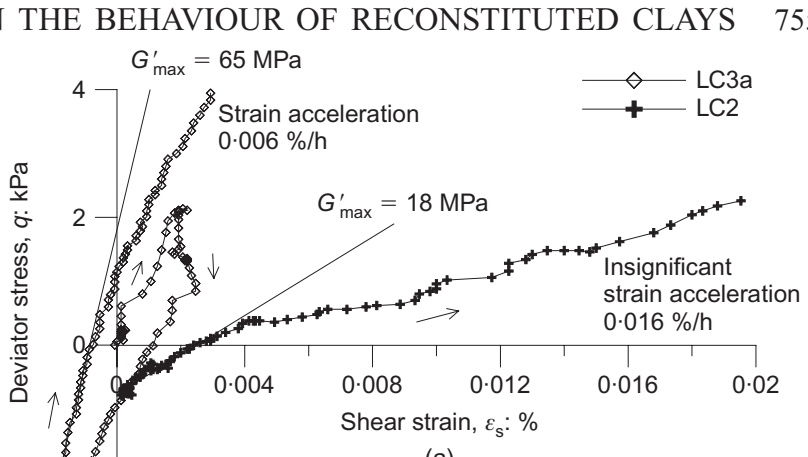

(a)

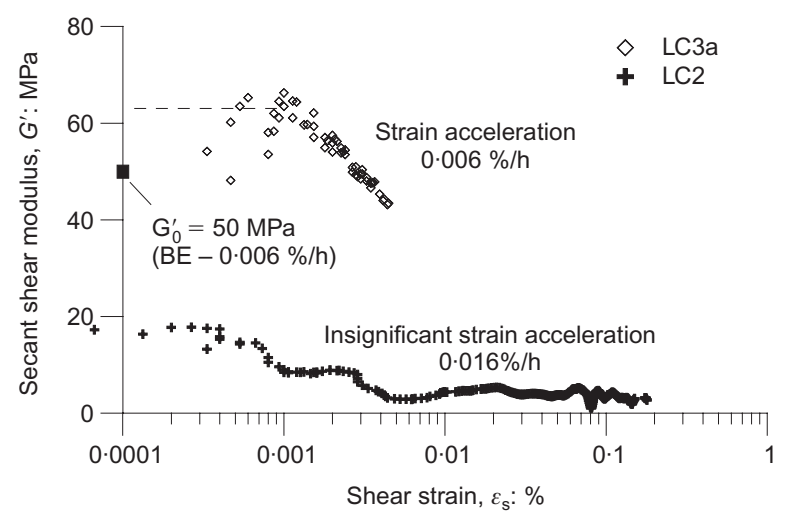

(b)

Fig. 5. (a) Stress-strain response and (b) shear stiffness obtained from drained triaxial compression probes following isotropic compression on normally consolidated reconstituted London Clay $-p_{0}^{\prime}=300 \mathrm{kPa}$

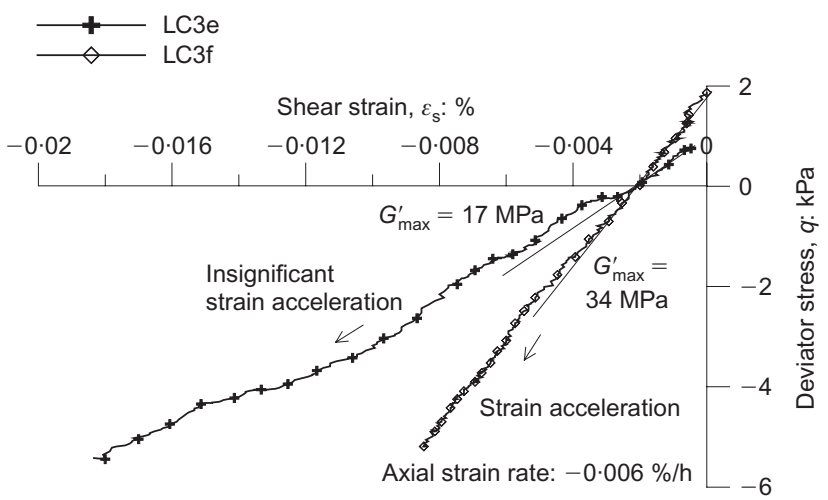

(a)

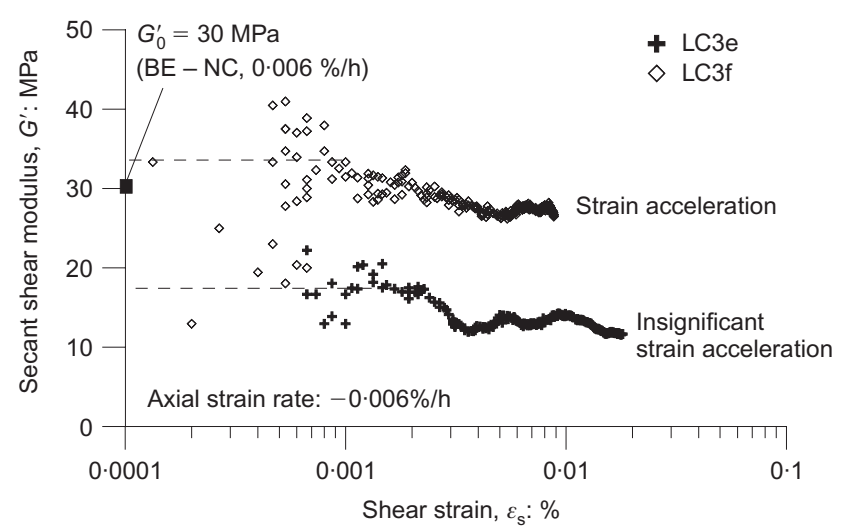

(b)

Fig. 6. (a) Stress-strain response and (b) shear stiffness obtained from drained triaxial extension probes on lightly overconsolidated ( $p_{0}^{\prime}=188 \mathrm{kPa}$ ) reconstituted London Clay, with different stress path and strain rate histories 


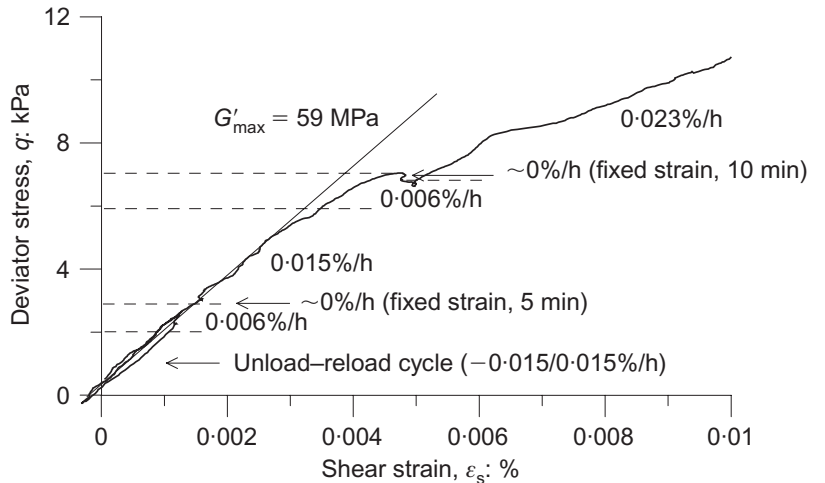

(a)

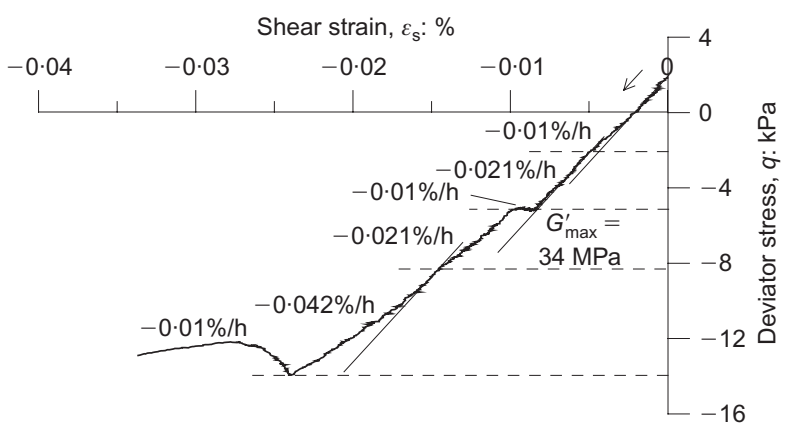

(b)

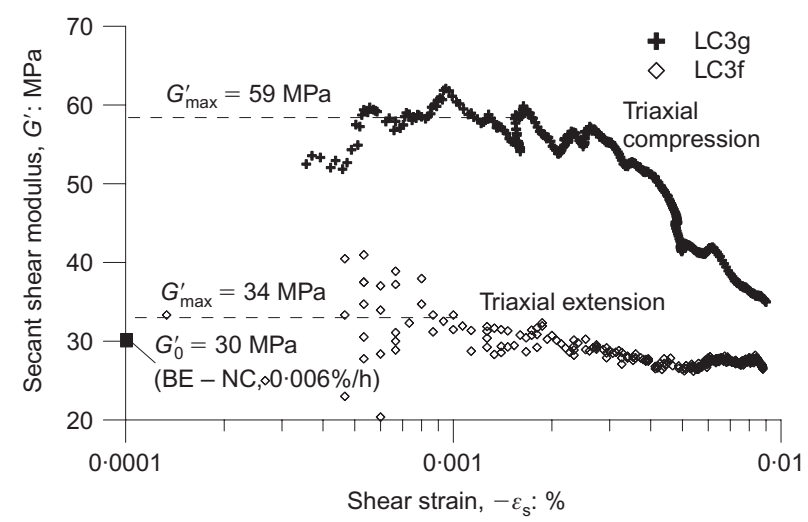

(c)

Fig. 7. Stress-strain response and shear stiffness obtained from drained triaxial compression and extension probes on lightly overconsolidated ( $p_{0}^{\prime}=188 \mathrm{kPa}$ ) reconstituted London Clay, with different stress path and strain rate histories: (a) test LC3g; (b) test LC3f; (c) shear modulus

using the stress paths shown in Fig. 1 and Table 2. In tests $\mathrm{LC} 2, \mathrm{LC} 3 \mathrm{a}$ and $\mathrm{LC} 3 \mathrm{e}$, the stress path rotation in $q-p^{\prime}$ space between compression (swelling for LC3e) and shearing is the same, equal to $72^{\circ}$. In test LC3f the specimen was subjected to a $180^{\circ}$ rotation, while in test LC3g there was no stress path rotation $\left(0^{\circ}\right)$. Different periods of rest were imposed on to the specimen between the different probes, which may have varied the effect of recent stress history.

The strain rate histories of the specimens that followed the same stress history, LC2, LC3a and LC3e, were chosen to be different (Figs 5(a) and 6(a)): in tests LC2 and LC3e, the specimens were sheared at an axial strain rate equal to the remaining axial creep rate after compression and swelling respectively, while in test LC3a the specimen was accelerated at the start of shearing by increasing the strain rate by a factor of 4 . The shear moduli calculated from the LVDTs measurements are shown in Figs 5(b) and 6(b), and results from the tests are summarised in Table 2, where the stiffness $G^{\prime}$ measured using the LVDTs at $0.0002 \%$ shear strain has been normalised for the current stress state $p^{\prime}$. In tests LC2 and LC3e, with no acceleration at the start of shearing, the values of $G^{\prime} / p^{\prime}$ are equal to about 60 and 95 respectively. In test $\mathrm{LC} 3 \mathrm{a}$, where the testing axial strain rate was multiplied by 4 , the value of $G / p^{\prime}$ is equal to about 215 , approximately three times the corresponding non-accelerated specimens. The specimen in test LC3a was further subjected to a small unload-reload cycle (Fig. 5(a)), and it is interesting to note that the value of shear modulus measured at the start of LC3a is similar to the value measured after stress reversal on reloading, which is thought to correspond to the elastic shear modulus.

For the extension probe LC3f , which was subjected to a stress path reversal, the testing axial strain rate was multiplied by 20 at the start of shearing (Fig. 7(a)), while for the compression probe LC3g, which continued in the same direction as the approach path, it was multiplied by 75 (Fig. 7(b)). The shear moduli calculated from the LVDTs' measurements are shown in Fig. 7(c). The measured values of $G^{\prime} / p^{\prime}$ for these two tests were found to be about 180 and 315 respectively. It is clear that the strain rate history has erased most of the recent stress path history. In effect, in the three tests where the specimen was accelerated at the start of shearing, the normalised values of stiffness are three to four times the values found in the tests where no acceleration took place, irrespective of changes in stress path. The difference between the values for LC2 and LC3e, and LC3a,f and LC3g, is about the same, the value for the compression tests being about 1.5 times that for the extension tests, and is thought to be due to the effects of anisotropy of the clay during compression and extension. The values obtained from bender element tests performed during the shearing are shown on the graphs for information, but they cannot be used for direct comparison.

\section{EFFECT OF SHEAR STRAIN ACCELERATION ON THE SHEAR MODULUS WITHIN THE ELASTIC REGION}

In tests LC3f and LC3g the specimens were subjected to a series of acceleration/deceleration events during the shearing stage, shown in Fig. 7 and described below. At the start of probe $\mathrm{LC} 3 \mathrm{~g}$, the specimen was left to rest for eleven days, at which point the axial strain rate had reduced to $0.0002 \% / \mathrm{h}$. The shearing started with a short unload-reload cycle $( \pm 2 \mathrm{kPa})$ with an axial strain rate of $0.015 \% / \mathrm{h}$, thus 75 times larger than the remaining axial creep strain rate, during which the behaviour was seen to be approximately linear. On reaching $q=2 \mathrm{kPa}$ on reloading, at a shear strain of about $0.0008 \%$, the strain rate was reduced to $0.006 \% / \mathrm{h}$ and kept constant until $q=3 \mathrm{kPa}$, corresponding to a shear strain of $0.0015 \%$, when the strain rate was increased again to $0.015 \% / \mathrm{h}$. From Fig. 7 (a) the stress-strain response for probe LC3g shows no obvious change of slope until about $0.0025 \%$ shear strain, at which point the soil gradually yields and the response becomes softer. This shows that $0.0025 \%$ is the limit of linear elastic behaviour, and that the value of the elastic stiffness remains constant despite changes in strain rate. It is thus clear that the stiffness of reconstituted London Clay is independent of strain rate within the elastic region.

\section{EFFECT OF STRAIN RATE AND TIME ON THE DYNAMIC SHEAR MODULUS DURING ISOTROPIC COMPRESSION ON THE NCL}

The dynamic stiffness of soils measured by bender elements is usually assumed to be elastic and independent of strain rate. Data presented earlier showed that indeed, where step-wise changes of axial strain rate are carried out before 
reaching yield (within the elastic region), there is no effect of the strain rate on the elastic shear modulus measured by static methods. In the following, results from isotropic compression tests on reconstituted London Clay (tests LC-iso1 and LC-iso2) and kaolin (test K-iso) are shown, where bender element tests were carried out during compression on the NCL. The tests were stress controlled and carried out with step changes in the applied rate of confining pressure. During testing, fixed effective stress creep stages were imposed on the specimens at different stress levels, for periods up to one month. Details are summarised in Table 3.

The dynamic shear modulus of clays measured by bender elements, $G_{0}$, is well known to depend on stress and state (e.g. Houlsby \& Wroth, 1991; Viggiani \& Atkinson, 1995). Fig. 8(a) (test K-iso) shows the variation in $G_{0}$ with the mean effective stress, $p^{\prime}$ during isotropic compression of kaolin, resulting from step changes in the axial stress rate, and stages of fixed effective stress creep at different stress levels. As demonstrated for example by Viggiani \& Atkinson (1995), there is a linear correlation between the logarithm of the mean effective stress and the logarithm of the dynamic shear modulus in normally consolidated states, which can be expressed as

$$
\frac{G_{0}}{p_{\mathrm{r}}}=A\left(\frac{p^{\prime}}{p_{\mathrm{r}}}\right)^{n}
$$

where $A$ and $n$ are positive constants, and $p_{\mathrm{r}}$ is a reference pressure usually taken as equal to $1 \mathrm{kPa}$. This was found to fit London Clay data from tests on natural and reconstituted specimens by Gasparre et al. (2007a). The data in Fig. 8(b) (test K-iso; creep data excluded for clarity) show that there are a number of linear relationships for the kaolin, which seem to depend on the applied stress rate (indirectly the applied strain rate). The data plot on approximately parallel straight lines, with a slope which can be represented by a constant value of the parameter $n$, but with varying intercepts (which would be $\ln (A)$ according to the notation of Viggiani \& Atkinson (1995) in equation (2)). This indicates that the parameter $A$ depends on the axial strain rate imposed to the sample externally. Here the axial strain rate is applied indirectly as stress rate through the cell pressure, and will be different to the strain rate imposed internally by the propagating shear wave during the bender element testing. There are slight deviations from the straight lines that define contours of strain rate at higher stress levels, but this is likely to be a result of the gradual reduction in strain rate with increasing stress level during the constant stress rate stages.

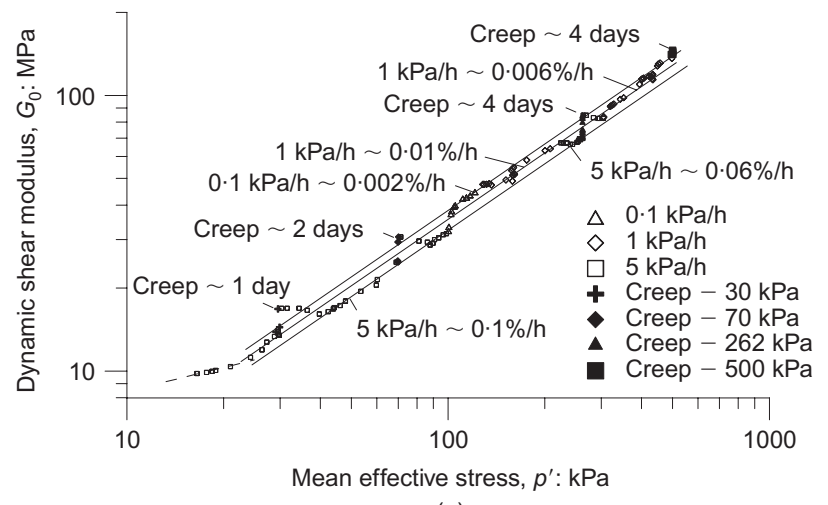

(a)

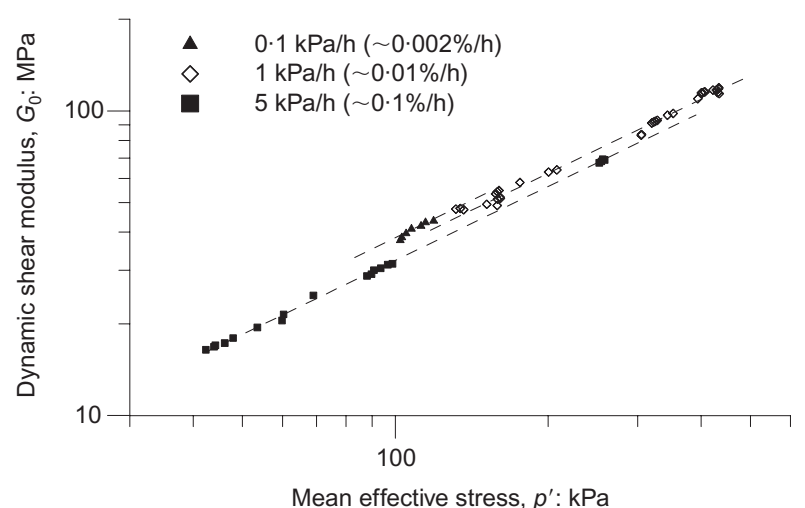

(b)

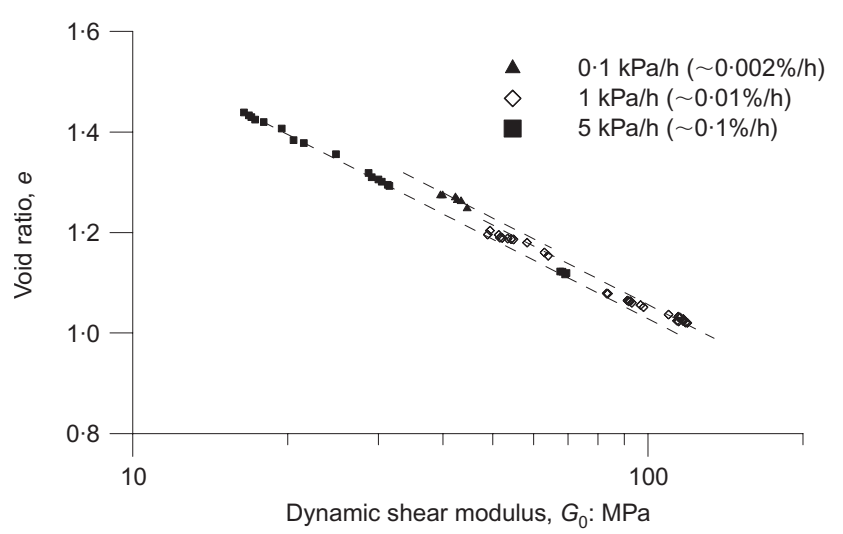

(c)

Fig. 8. Effect of changing the testing axial strain rate during isotropic compression of normally consolidated kaolin (test $\mathrm{K}$ iso): (a) and (b) $\log G_{0}-\log p^{\prime}$; (c) $e-\log G_{0}$

Table 3. Summary of isotropic test results

\begin{tabular}{|c|c|c|c|c|c|c|}
\hline & LC-iso1 & LC-creep1 & LC-iso2 & LC-creep2 & $\mathrm{K}$-iso & K-creep \\
\hline Compression & $\begin{array}{l}\text { Isotropic } \\
\text { compression to } \\
p^{\prime}=300 \mathrm{kPa}\end{array}$ & $\begin{array}{l}\text { Creep stage } \\
p^{\prime}=300 \mathrm{kPa}\end{array}$ & $\begin{array}{l}\text { Isotropic } \\
\text { compression to } \\
p^{\prime}=132 \mathrm{kPa}\end{array}$ & $\begin{array}{l}\text { Creep stage } \\
p^{\prime}=132 \mathrm{kPa}\end{array}$ & $\begin{array}{l}\text { Isotropic } \\
\text { compression to } \\
p^{\prime}=300 \mathrm{kPa}\end{array}$ & $\begin{array}{l}\text { Creep stages } \\
p^{\prime}=30,70,262, \\
500 \mathrm{kPa}\end{array}$ \\
\hline Duration of creep & & 26 days & & 22 days & & $1,2,4,4$ days \\
\hline $\begin{array}{l}\text { Testing axial stress } \\
\text { rate* }^{*}\end{array}$ & $0 \cdot 3$ and $3 \mathrm{kPa} / \mathrm{h}$ & - & $0 \cdot 3$ and $3 \mathrm{kPa} / \mathrm{h}$ & - & $0 \cdot 1,1$ and $5 \mathrm{kPa} / \mathrm{h}$ & - \\
\hline Axial strain rate ${ }^{\dagger}$ & 0.007 and $0.07 \% / \mathrm{h}$ & - & 0.007 and $0.07 \% / \mathrm{h}$ & - & $0.002,0.01$ and $0.1 \% / \mathrm{h}$ & - \\
\hline $\begin{array}{l}\text { Reference axial } \\
\text { strain rate: } \% / \mathrm{h}\end{array}$ & $0 \cdot 07$ & $0 \cdot 07$ & $0 \cdot 07$ & $0 \cdot 07$ & $0 \cdot 10$ & $0 \cdot 10$ \\
\hline
\end{tabular}

\footnotetext{
* Computer-controlled.

$\dagger$ Measured using Hall effect transducers.
} 
Clear effects of the applied axial strain rate are also noted when plotting the void ratio, $e$, against the logarithm of the dynamic shear modulus, $G_{0}$ (Fig. 8(c), test K-iso; creep data excluded for clarity). Again the data plot on approximately parallel lines which can be expressed by an exponential of the form

$$
\frac{G_{0}}{p_{\mathrm{r}}}=A^{\prime} \exp \left(-n^{\prime} e\right)
$$

where $A^{\prime}$ and $n^{\prime}$ are positive constants, and $p_{\mathrm{r}}$ is a reference pressure usually taken as equal to $1 \mathrm{kPa}$. For these data on kaolin for example, at a given void ratio, an increase in axial strain rate by ten-fold $(0 \cdot 01 \% / \mathrm{h}$ to $0 \cdot 1 \% / \mathrm{h})$ seems to be accompanied by a decrease in $G_{0}$ of about $10 \%$. Tables 4 and 5 summarise the values for the parameters $A, n, A^{\prime}$ and $n^{\prime}$ for the specimens tested.

Results from isotropic compression tests on reconstituted London Clay (tests LC-iso1 and LC-iso2) show a similar influence of strain rate on the relationships between $G_{0}$, $e$ and $p^{\prime}$ (Fig. 9). The observed effects of changes in strain rate on the NCL seem to be directly matched by effects on $G_{0}$. For a given void ratio, an increase in strain rate ten-fold, in the example from $0.007 \% / \mathrm{h}$ to $0.07 \% / \mathrm{h}$, gives rise to an increase in yield stress and a decrease of the dynamic shear modulus of about $12 \%$. This dependence of strain rate is apparently in contradiction with the previous data showing that the elastic stiffness is independent of strain rate, but these were based on static measurements of the shear modulus in the elastic region, while the data are now presenting dynamic measurements of stiffness while the soil is experiencing plastic straining.

The upward shift of the NCL with increasing strain rate is well known and has been described for example by Bjerrum (1967). While the data shown in Figs 9(b) and 9(c) $\left(\ln p^{\prime}-\right.$ $\ln G_{0}$ plot, tests LC-iso1 and LC-iso2) and Fig. 9(d) (e$\ln G_{0}$ plot, test LC-iso1) indicate that the dynamic shear modulus is decreasing with increasing testing axial strain rate, however, the upward shift of the NCL with increasing strain rate (Fig. 9(a), test LC-iso1) indicates an increase in the overall compression modulus, as measured by the ratio of change in stress to change in strain at given void ratio.
Similar behaviour was observed in tests LC-isol and LCiso2, although only data from LC-iso1 are shown in Figs 9(a) and 9(d) for clarity. There must thus be effects of changing strain rate on the dynamic shear modulus that are not due to the changes in stress and density in the sample, but are additional effects that can be directly correlated to the current strain rate. The increase in dynamic shear modulus with reducing strain rate is in agreement with the usual observation that during creep the strain rate decreases with time but the dynamic shear modulus increases (Mitchell \& Soga, 1997; Lohani et al., 2001). Supporting data are given in Table 6 for the creep stage LC-creep1 (test LC-iso1). The next section presents a method to normalise the dynamic shear modulus for stress and strain rate, with a view to explaining the increase in dynamic shear modulus usually observed during creep.

\section{A NEW METHOD TO ACCOUNT FOR STRESS AND STRAIN RATE FOR EVALUATING THE DYNAMIC SHEAR MODULUS}

Because the dynamic shear modulus has been shown to depend on stress level (Viggiani \& Atkinson, 1995; Gasparre et al., 2007a), the values of shear modulus have been normalised with respect to an equivalent modulus for the normally consolidated soil at the same mean effective stress, using the line defined by equation (2). The values taken for that line are given for the tested specimens of reconstituted London Clay and for the kaolin in Table 4. However, it was shown earlier that that line is not unique but depends on the strain rate at which the sample is being compressed. It is thus necessary to define a reference axial strain rate $\dot{\varepsilon}_{\mathrm{a} \text {,ref }}$, taken here as $0.07 \% / \mathrm{h}$ for London Clay and $0 \cdot 1 \% / \mathrm{h}$ for kaolin, for which the linear relationship between $G_{0}$ and $p^{\prime}$ is defined. The equivalent shear modulus taken on that reference line is referred to as $G_{0, \text { ref }}$ and illustrated in Fig. 10. For convenience, $R_{\alpha}$ is introduced, and defined by

$$
R_{\alpha}=\frac{G_{0}}{G_{0, \text { ref }}}
$$

The normalised stiffness $R_{\alpha}$ has been plotted against the

Table 4. Non-dimensional soil parameters $\boldsymbol{A}$ and $\boldsymbol{n}$ - relating $\boldsymbol{G}_{\mathbf{0}}$ to $\boldsymbol{p}^{\prime *}$

\begin{tabular}{l|l|c|c|c|c|c}
\hline Test & Material & $\begin{array}{c}\text { Reference confining } \\
\text { stress rate: } \mathrm{kPa} / \mathrm{h}\end{array}$ & $\begin{array}{c}\text { Reference axial strain } \\
\text { rate: }{ }^{\dagger} \% / \mathrm{h}\end{array}$ & $A$ & $n$ & $R^{2 \dagger}$ \\
\hline LC-iso1 & r. London Clay & 3 & $0 \cdot 07$ & 302 & $0 \cdot 873$ & $0 \cdot 9998$ \\
LC-iso2 & r. London Clay & 3 & $0 \cdot 07$ & 546 & $0 \cdot 741$ & $0 \cdot 9910$ \\
K-iso & r. kaolin & 5 & $0 \cdot 1$ & 807 & $0 \cdot 800$ & 0.9990 \\
\hline
\end{tabular}

${ }^{*} G_{0} / p_{\mathrm{r}}=A\left(p^{\prime} / p_{\mathrm{r}}\right)^{n}\left(\right.$ Viggiani \& Atkinson, 1995). $p_{\mathrm{r}}=1 \mathrm{kPa}$

${ }^{\dagger}$ Average strain rate under stress-controlled loading.

$\$$ Coefficient of determination.

Table 5. Non-dimensional soil parameters $A^{\prime}$ and $n^{\prime}-$ relating $G_{0}$ to $e^{*}$

\begin{tabular}{l|l|c|c|c|c|c}
\hline Test & Material & $\begin{array}{c}\text { Reference confining } \\
\text { stress rate: } \mathrm{kPa} / \mathrm{h}\end{array}$ & $\begin{array}{c}\text { Reference axial strain } \\
\text { rate: } \% / \mathrm{h}\end{array}$ & $A^{\prime}$ & $n^{\prime}$ & $R^{2 \ddagger}$ \\
\hline LC-iso1 & r. London Clay & 3 & $0 \cdot 07$ & 1288 & 3.946 & 0.99995 \\
LC-iso2 & r. London Clay & 3 & $0 \cdot 07$ & 1122 & $3 \cdot 771$ & 0.994 \\
K-iso & r. kaolin & 5 & $0 \cdot 1$ & 10464 & 4.485 & 0.9990 \\
\hline
\end{tabular}

${ }^{*} G_{0} / p_{\mathrm{r}}=A^{\prime} \exp ^{-n^{\prime} e} \cdot p_{\mathrm{r}}=1 \mathrm{kPa}$.

${ }^{\dagger}$ Average strain rate under stress-controlled loading.

$\$$ Coefficient of determination. 


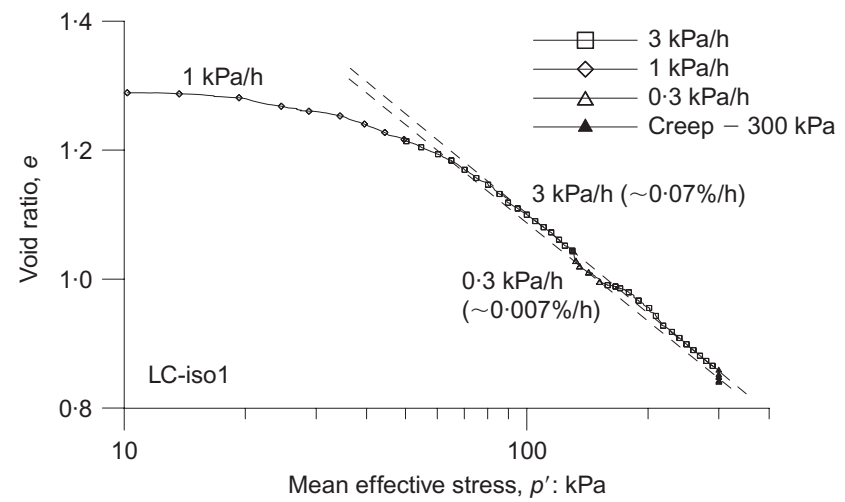

(a)

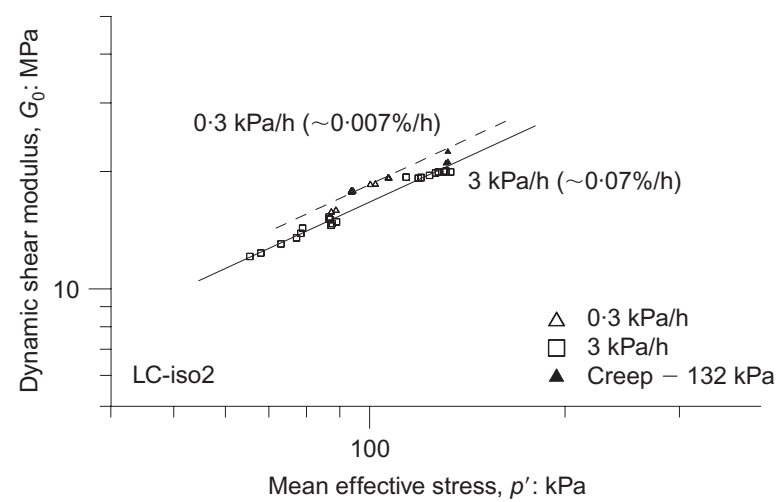

(c)

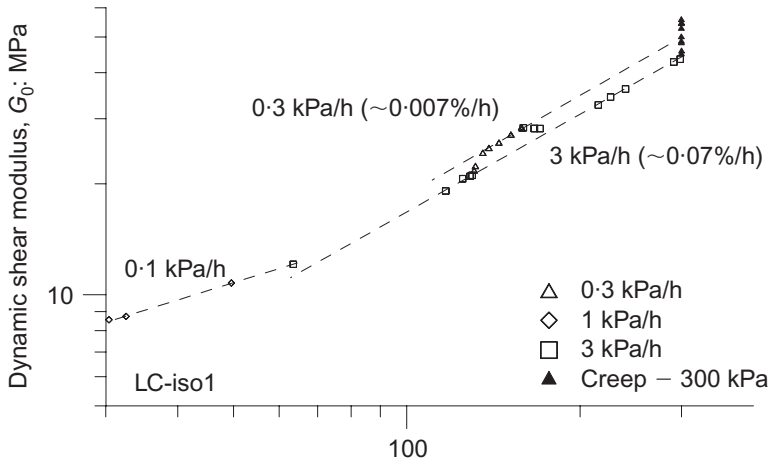

Mean effective stress, $p^{\prime}: \mathrm{kPa}$

(b)

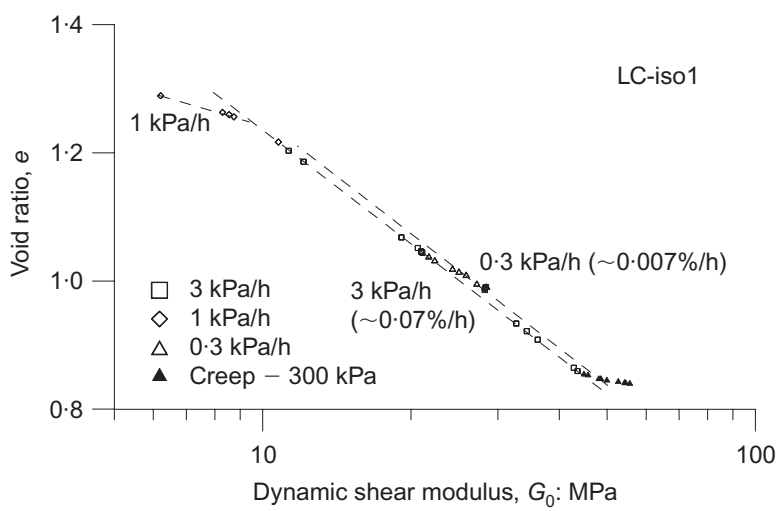

(d)

Fig. 9. Effect of changing the testing axial strain rate during isotropic compression of normally consolidated reconstituted London Clay: (a) $e-\log p^{\prime}$ (test LC-iso1); (b) and (c) $\log G_{0}-\log p^{\prime}$ (tests LC-iso1 and LC-iso2); (d) $e-\log G_{0}$ (test LC-iso1)

Table 6. Comparison between predicted and measured $G_{0}$ during creep $\left(p^{\prime}=300 \mathrm{kPa}\right.$, LC-creep1)

\begin{tabular}{l|c|c|c|c|c}
\hline Creep time: days & $e$ & Strain rate: $\% / \mathrm{h}$ & $G_{0}$ measured: MPa & $G_{0}^{\text {pred }}$ predicted: ${ }^{*}$ MPa & Ratio $G_{0} / G_{0}^{\text {pred }}$ \\
\hline 0 & $0 \cdot 8594$ & 0.03 & 44 & 43 & 0.98 \\
1 & $0 \cdot 8471$ & 0.003 & 48 & 46 & $1 \cdot 05$ \\
10 & 0.8410 & 0.0003 & 54 & 47 & $1 \cdot 15$ \\
\hline
\end{tabular}

* Prediction based on void ratio reduction only; using $G_{0} / p_{\mathrm{r}}=A^{\prime} \exp ^{-n^{\prime} e} . p_{\mathrm{r}}=1 \mathrm{kPa}, A^{\prime}=1288, n^{\prime}=3.946$.

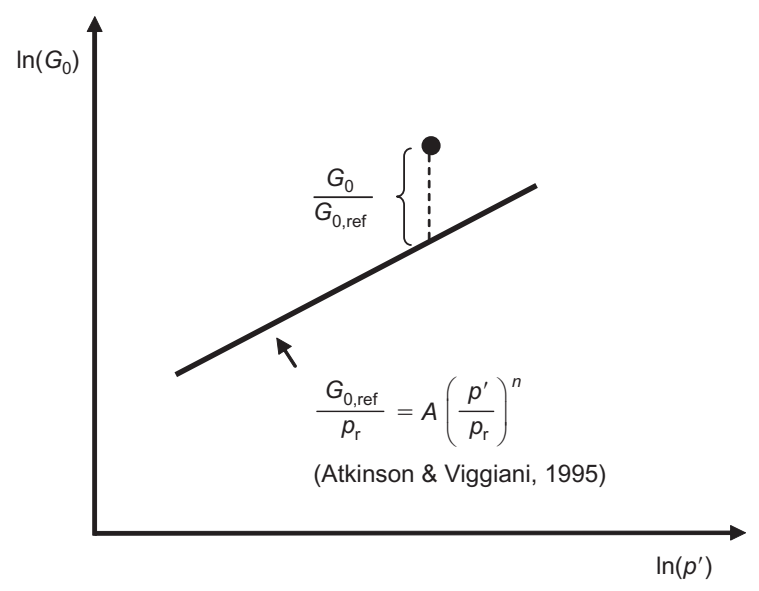

Fig. 10. Normalising the dynamic shear modulus with respect to a reference axial strain rate at a given stress level

axial strain rate $\dot{\varepsilon}_{\mathrm{a}}$ in Fig. 11 for each of the tested specimens of reconstituted London Clay and kaolin. The plots include data from step-wise changes in stress rate and stages of fixed effective stress creep during isotropic compression.
Some scatter is observed in the data, which to a large degree might be explained by inaccuracies in the measurement of the axial strain rate. A better correlation may also have been obtained by expressing the dependence of $G_{0}$ on strain rate in terms of plastic strain rate rather than the total strain rate. A clear trend is, however, observed, with the plotted data forming a relatively narrow band around a straight line, which relates uniquely dynamic shear modulus and axial strain rate for a given stress. This can be described by the equation

$$
R_{\alpha}=1-\alpha \log \left(\frac{\dot{\varepsilon}_{\mathrm{a}}}{\dot{\varepsilon}_{\mathrm{a}, \mathrm{ref}}}\right)
$$

where $\alpha$ is a new parameter, which can be expressed as

$$
\alpha=-\frac{\Delta\left(G_{0} / G_{0, \mathrm{ref}}\right)}{\Delta \log \dot{\varepsilon}_{\mathrm{a}}}
$$

The tested specimens of reconstituted London Clay and kaolin are found to give similar values of $\alpha$ (see Table 7) around approximately $0 \cdot 12$, corresponding to a $12 \%$ increase in $G_{0}$ per $\log$ reduction in axial strain rate. These values were found by using the data from both the constant stress 


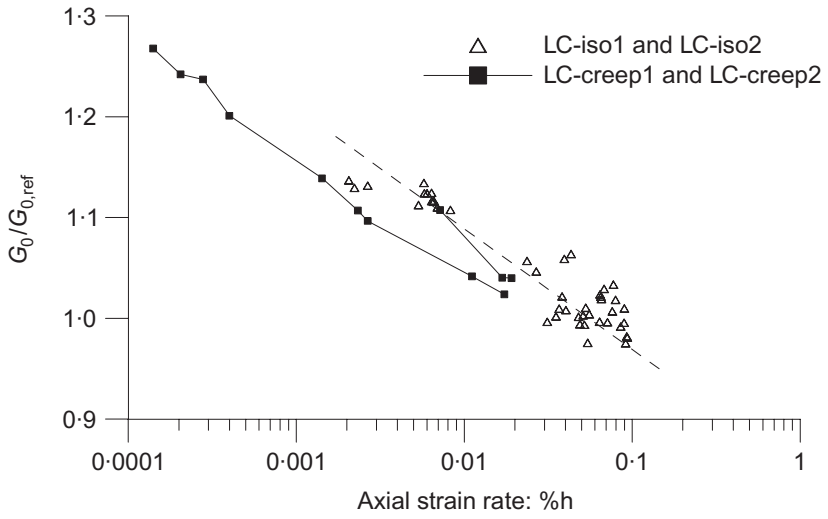

(a)

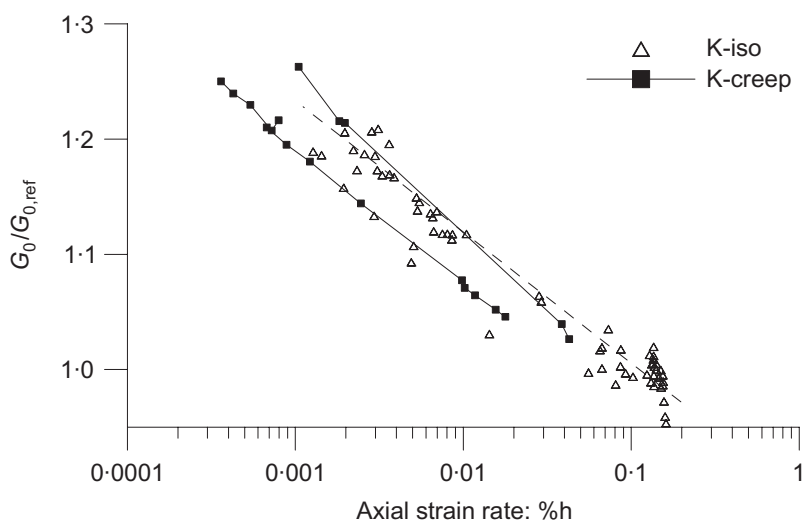

(b)

Fig. 11. Relationship between normalised dynamic shear modulus and testing axial strain rate during isotropic compression and creep; data from tests on normally consolidated reconstituted specimens of (a) London Clay and (b) kaolin

rate isotropic compression and the fixed effective stress stages.

The dynamic shear modulus $G_{0}$ is generally found to increase with time during stages of fixed stress creep, as was shown for example by Rammah et al. (2004) with data from reconstituted London Clay. Anderson \& Stokoe (1978) proposed a coefficient of shear modulus increase with time $I_{\mathrm{G}}$ to describe the long-term effect of creep on the dynamic shear modulus

$$
I_{\mathrm{G}}=\frac{\Delta G_{0}}{\log \left(t_{2} / t_{1}\right)}
$$

where $\Delta G_{0}$ is the change in dynamic shear modulus from time $t_{1}$ to time $t_{2}$ after the end of primary consolidation. To remove the influence of confining pressure, Anderson \& Stokoe (1978) proposed further normalisation

$$
N_{\mathrm{G}}=\frac{I_{\mathrm{G}}}{G_{0,1000}}
$$

where $G_{0,1000}$ is the dynamic shear modulus measured after 1000 minutes of creep (which must be after the end of primary consolidation) and $N_{\mathrm{G}}$ is the normalised increase in shear modulus with time. They found values of $N_{\mathrm{G}}$ between 2 and 40 for a wide range of undisturbed clays, with values for soft clays in the higher range and values for stiff clays or sands in the lower range.

During the tests LC-iso1, LC-iso2 and K-iso presented here, fixed effective confining stress creep stages were imposed at different stress levels (LC-creep1, LC-creep2 and K-creep respectively, in Table 3). Because the tests were strain controlled, and because strain rates slow enough to avoid any significant build-up of excess pore water pressure were used, it was assumed that the specimens were normally consolidated at all times. In test LC-creep1, the reconstituted London Clay specimen experienced a creep period for about four weeks at a stress level of $p^{\prime}=300 \mathrm{kPa}$, while in test LC-creep2, the specimen experienced a creep period of about three weeks at $p^{\prime}=132 \mathrm{kPa}$. In both tests, when creep was initiated the stress rate was $3 \mathrm{kPa} / \mathrm{h}(\sim 0 \cdot 07 \% / \mathrm{h})$. During compression of the kaolin specimen (K-iso) four short-term stages of creep were imposed, with varying length of up to four days at different stress levels. Creep was initiated at mean effective stresses of $30 \mathrm{kPa}, 70 \mathrm{kPa}$ and $262 \mathrm{kPa}$, at which points the stress rate was measured to be $5 \mathrm{kPa} / \mathrm{h}$ $(\sim 0.06 \% / \mathrm{h})$, and at $p^{\prime}=500 \mathrm{kPa}$ where the stress rate was measured as $1 \mathrm{kPa} / \mathrm{h}(\sim 0 \cdot 01 \% / \mathrm{h})$ at the start of the creep stage.

The measured reductions in axial strain rate with time during creep are plotted on double logarithmic scales in Figs 12(a) and 12(b) for tests LC-creep1 and LC-creep2 on reconstituted London Clay, and Fig. 12(c) for the test Kcreep on kaolin. The corresponding changes in $G_{0}$ with time during the creep stages tests are shown in Fig. 13, where it can be observed that the data points for the three tests fall close to straight lines as expected. The coefficients $I_{\mathrm{G}}$ and

\begin{tabular}{|c|c|c|c|c|c|c|c|c|c|c|}
\hline \multirow[t]{2}{*}{ Test } & \multicolumn{2}{|c|}{ Isotropic compression } & \multicolumn{8}{|c|}{ Creep } \\
\hline & $C_{\mathrm{c}}$ & $\alpha$ & $p^{\prime}$ creep: $\mathrm{kPa}$ & $\begin{array}{l}\text { Creep time: } \\
\text { days }\end{array}$ & $C_{\alpha}$ & $m^{*}$ & $I_{\mathrm{G}}^{\dagger}$ & $N_{\mathrm{G}}^{\dagger}$ & $\begin{array}{c}N_{\mathrm{G}}^{*+} \\
\left(N_{\mathrm{G}}^{*}\right)^{\S}\end{array}$ & $\alpha^{3}$ \\
\hline LC-iso1 & $0 \cdot 51$ & $0 \cdot 12$ & 300 & 26 & 0.0048 & $\sim 1$ & 5100 & $0 \cdot 11$ & $\begin{array}{c}0 \cdot 12 \\
(0 \cdot 12)\end{array}$ & $0 \cdot 12$ \\
\hline LC-iso2 & $(0.41)$ & $0 \cdot 11$ & 132 & 22 & 0.0052 & $\sim 1$ & 2200 & $0 \cdot 10$ & 0.11 & - \\
\hline \multirow{4}{*}{ K-iso } & 0.41 & $0 \cdot 12$ & 30 & 1 & $0 \cdot 0053$ & - & 1700 & 0.08 & $0 \cdot 13$ & - \\
\hline & & & 70 & 2 & 0.0048 & $\sim 1$ & 3200 & 0.09 & $\begin{array}{c}0.13 \\
(0.14)\end{array}$ & $0 \cdot 14$ \\
\hline & & & 262 & 4 & $0 \cdot 0043$ & $\sim 1$ & 7000 & 0.08 & $0 \cdot 10$ & $0 \cdot 12$ \\
\hline & & & 500 & 4 & $0 \cdot 00073$ & $\sim 0.6$ & 8700 & 0.06 & $\begin{array}{c}0.06 \\
(0.07)\end{array}$ & $0 \cdot 12$ \\
\hline
\end{tabular}

Table 7. Compression and time-related parameters

\footnotetext{
* Calculated from test data, as defined by Singh \& Mitchell (1968).

$\dagger$ Calculated from test data, as defined by Anderson \& Stokoe (1978).

$\$$ Calculated from test data, as defined in text.

$\S$ Calculated using proposed equation (11): $N_{\mathrm{G}}^{*}=\alpha m$.
} 


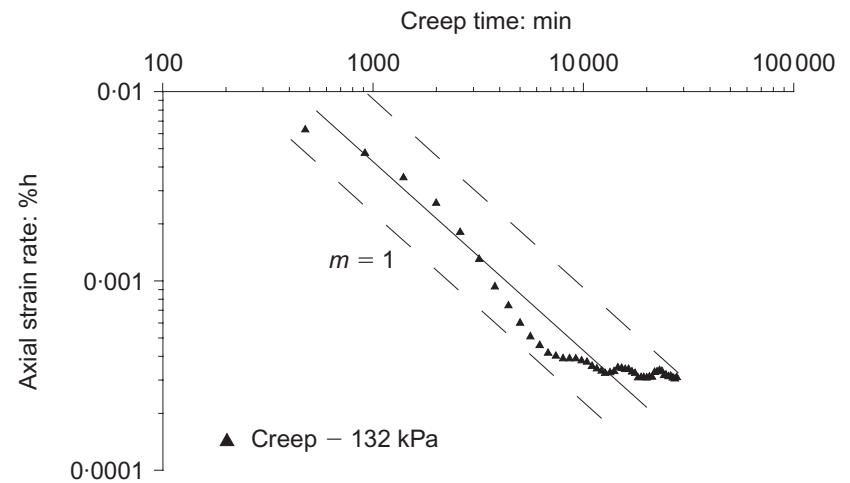

(a)

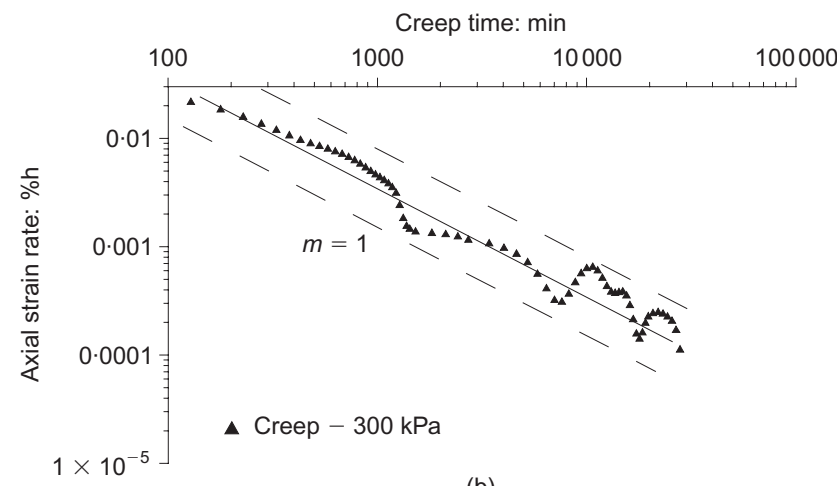

(b)

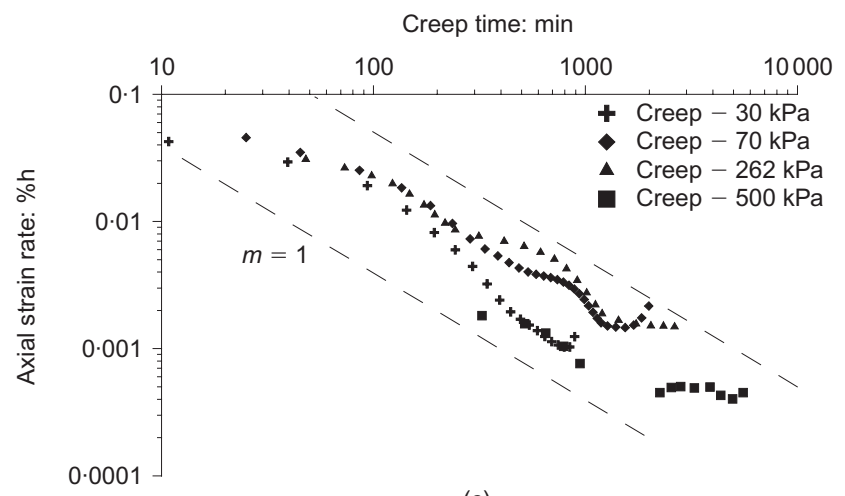

(c)

Fig. 12. Relationship between decrease in axial strain rate and creep time, during creep isotropic stages on normally consolidated reconstituted London Clay: (a) test LC-creep2; (b) LC-creep1; (c) normally consolidated kaolin (test K-creep)

$N_{\mathrm{G}}$ were derived and are summarised in Table 7 . They are found to be of similar magnitude to those reported in the literature for other types of reconstituted soft clays (Lo Presti et al., 1996; Lohani et al., 2001). The limitation of using $N_{\mathrm{G}}$ is that it measures the relative increase of $G_{0}$ with time in relation to an arbitrary value of dynamic shear modulus, $G_{0,1000}$. These values do not take account of the strain rate to which the soil is subjected. During creep, the strain rate is known to decrease approximately linearly with the logarithm of time. The rate at which the decrease occurs has been quantified as $m$ by Singh \& Mitchell (1968) so that

$$
m=-\frac{\Delta \log \dot{\varepsilon}_{\mathrm{a}}}{\Delta \log t}
$$

Values of $m$ equal to approximately 1 have been calculated for the London Clay, based on the data shown in Fig. 12, and $m$ values for kaolin also seem to be close to 1 for creep stages initiated at the higher stress rate of $5 \mathrm{kPa} / \mathrm{h}$. For the creep stage which was initiated at the lower stress rate of

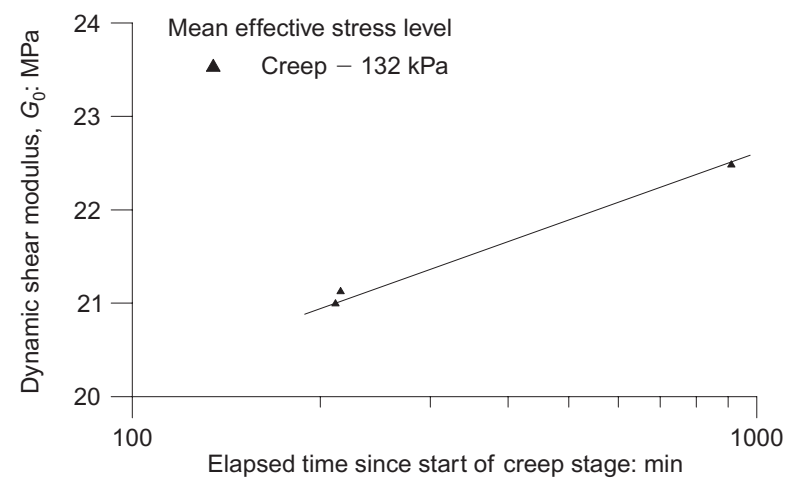

(a)

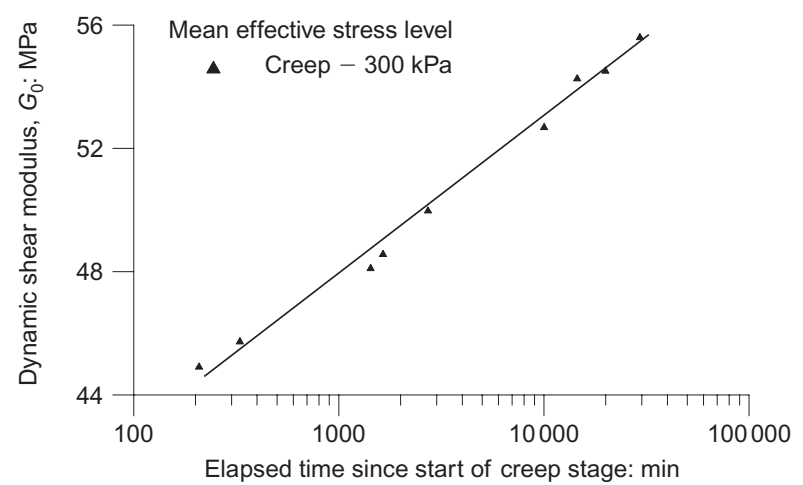

(b)

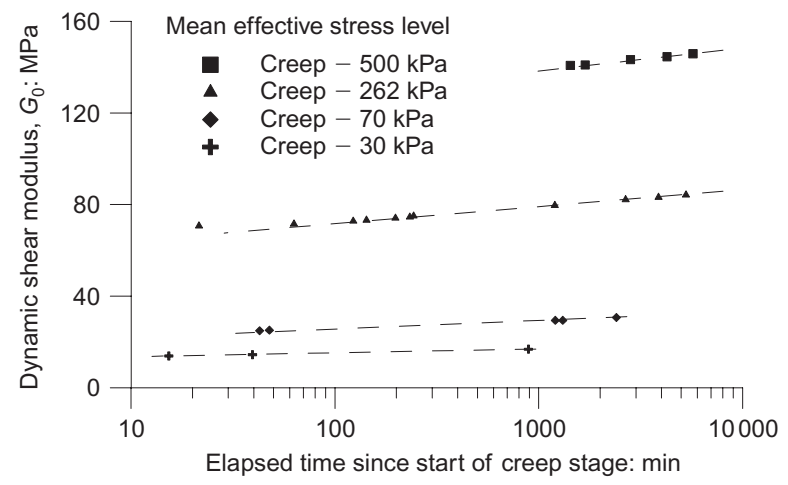

(c)

Fig. 13. Relationship between dynamic shear modulus and creep time, during creep isotropic stages on normally consolidated reconstituted London Clay: (a) test LC-creep2; (b) test LCcreep1; (c) normally consolidated kaolin (test K-creep).

$1 \mathrm{kPa} / \mathrm{h}$, there is a larger scatter in the data, attributed to lower accuracy in the strain measurements, and a lower $m$ value is calculated. The direct proportionality between changes in the logarithm of strain rate and the logarithm of time implies that the change in $G_{0}$ with the logarithm of time quantified by $I_{\mathrm{G}}$ could similarly be simply related to the logarithm of strain rate. A new quantifying coefficient $N_{\mathrm{G}}^{*}$ is proposed

$$
N_{\mathrm{G}}^{*}=\frac{\left(\Delta\left(G_{0} / G_{0, \mathrm{ref}}\right)\right)}{(\Delta \log t)}
$$

where the change in $G_{0}$ is normalised for stress level by a reference dynamic shear modulus, $G_{0, \text { ref }}$ taken at a reference strain rate at the given stress level (after the end of primary consolidation). Values of $N_{\mathrm{G}}^{*}$ have been calculated for each creep stage by implementing the test data directly into equation (10); they are given in Table 7. From the expres- 
sions for $\alpha$ (equation (6)) and $m$ (equation (9)), it seems that $N_{\mathrm{G}}^{*}$ can also be formulated as

$$
N_{\mathrm{G}}^{*}=\alpha m
$$

Equation (11) highlights that the dependence of $G_{0}$ on time observed during creep may be related to strain rate. Values of $N_{\mathrm{G}}^{*}$ were re-calculated using equation (11), and the values of $\alpha$ and $m$ derived for each specimen (see Table 7). The computed values are close to the values determined directly from the individual tests, indicating that the approach is not unreasonable, at least for creep test data obtained in the laboratory on reconstituted clay. It is thus proposed that the influence of state and strain rate on the dynamic shear modulus can be expressed in the following general form

$$
\frac{G_{0}}{p_{\mathrm{r}}}=A\left(\frac{p^{\prime}}{p_{\mathrm{r}}}\right)^{n} R_{\alpha}
$$

where $A$ and $n$ are the non-dimensional soil parameters obtained from the constant strain rate line defined by the reference axial strain rate $\dot{\varepsilon}_{a, \text { ref }}$, while the influence of strain rate is quantified by the quantity $R_{\alpha}$, as calculated by equation (5). The data from the constant rates of stress isotropic tests LC-iso1 and LC-iso2 have been re-plotted in Fig. 14(a) in terms of normalised stiffness, $G_{0} / R_{\alpha}$, against mean effective stress $p^{\prime}$, by taking the reference axial strain rate $0 \cdot 07 \% / \mathrm{h}$. According to equation (12), the data should plot on a straight line in a logarithmic plot, of intercept $\ln (A)$ and slope $n$. By taking the average values of $A$ $\left(A_{\text {ref }}=424\right)$ and $n\left(n_{\text {ref }}=0.807\right)$ determined for the specimens tested in LC-iso1 and LC-iso2 at axial strain rates of $0.07 \% / \mathrm{h}$, a straight line could be drawn, which also coincides with the isotropic test data. The creep test data at the end of the isotropic compression tests, under constant mean effective stresses of $132 \mathrm{kPa}$ and $300 \mathrm{kPa}$ in tests LC-iso1 and LC-iso2 (LC-creep1 and LC-creep2 respectively), have also been plotted. They also coincide with the reference line. A similar procedure was applied to data from isotropic compression (K-iso) and creep (K-creep) tests on kaolin (Fig. 14(b)), using the corresponding values of $A$ $\left(A_{\text {ref }}=807\right)$ and $n\left(n_{\text {ref }}=0 \cdot 800\right)$, and again, all data coincide well with the reference line. Thus, the parameter $R_{\alpha}$, which quantifies the axial strain rate relative to a reference strain rate, seems to be a good indicator of how the dynamic shear modulus changes with strain rate and time.

These results, of course, have been validated against data gathered in laboratory time-scale, and it is not unlikely that in longer terms the clay may develop additional bonding. The data were also obtained from tests on normally consolidated reconstituted London Clay, while it is known that London Clay has a natural structure that influences its behaviour (Gasparre et al., 2007a). Data from Sorensen et al. (2007) on intact and reconstituted (normally and overconsolidated) London Clay also showed that the effects of strain rate on the stress-strain response during shearing are influenced by structure. However, at small strains, Gasparre et al. (2007a) found that measurements of $G_{0}$ on intact specimens were only slightly greater at the in-situ stress than what was expected from the normally consolidated reconstituted specimens. This evidence is unfortunately not sufficient so far to anticipate what the effects of strain rate on $G_{0}$ would be on the intact clay, and more work would need to be carried out.

\section{CONCLUSIONS}

From the results presented above stem four main conclusions, as follows.

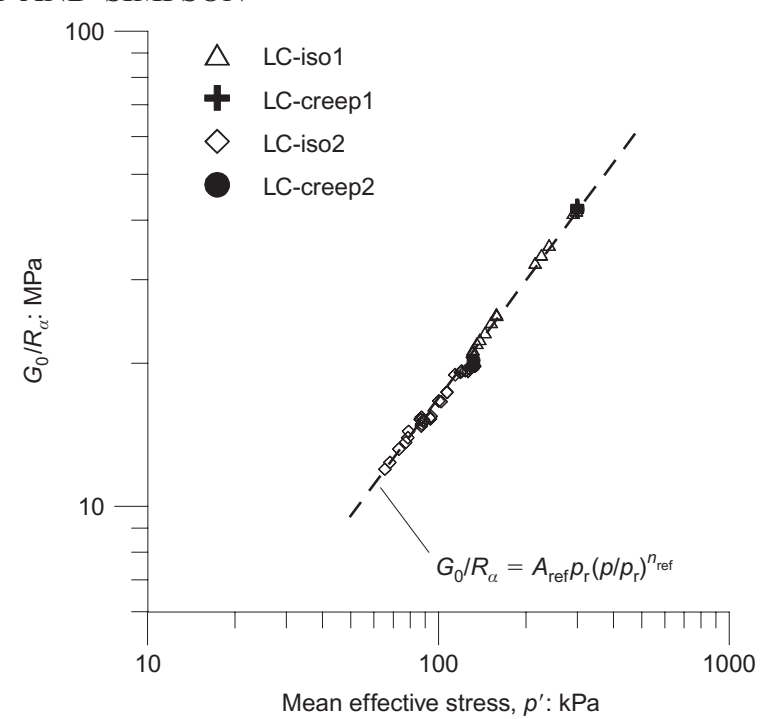

(a)

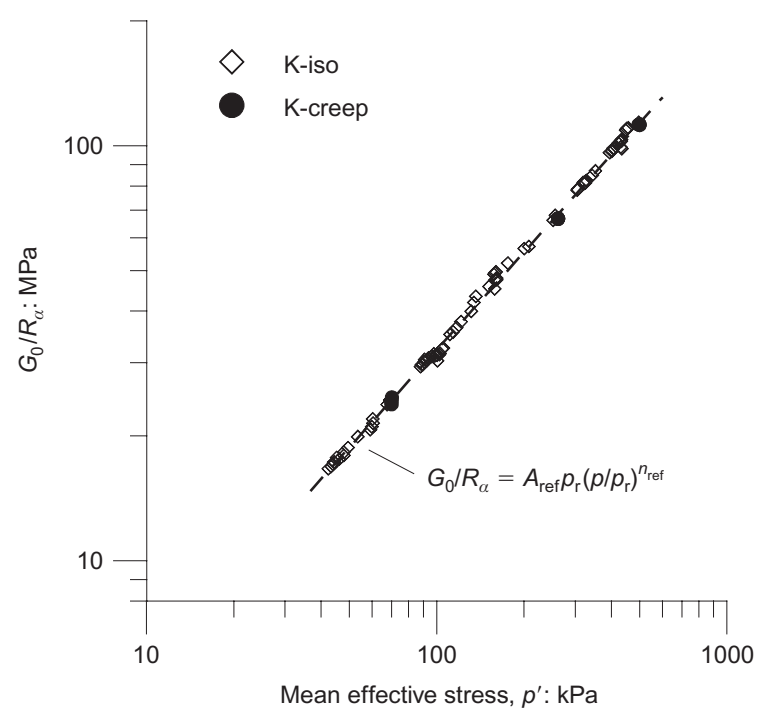

(b)

Fig. 14. Relationship between normalised dynamic shear modulus and mean effective stress; data from normally consolidated reconstituted specimens: (a) London Clay; (b) kaolin

(a) The temporary acceleration arising from an increase in axial strain rate results in very high values of stiffness measured at small strains. However, if the value of the testing axial strain rate chosen for shearing is close to the rate at which axial strains develop during creep after compression, the remaining creep strains influence the measurement of stiffness, with a risk of underestimating the shear modulus. This also implies that acceleration may overshadow effects of recent stress history, and that these cannot be dissociated from the strain rate history.

(b) The shear modulus measured at very small strains from local transducers is independent of strain rate when deformations are elastic.

(c) The dynamic shear modulus $G_{0}$ measured using bender elements on the NCL is dependent on the testing strain rate applied on the specimen.

(d) The increase in $G_{0}$ usually observed with time may be attributed to the decrease in strain rate in the specimen, when the creep period is short enough to avoid structuration (ageing) effects. The mechanisms underlying the rate- and time-dependency of the dynamic 
shear modulus may thus be similar, but further research would need to be done to confirm that.

\section{ACKNOWLEDGEMENTS}

The authors would like to thank Imperial College for providing the rotary cores of undisturbed London Clay, without which this research could not have been carried out, and Dr Coop for his guidance and help with the experimental testing at the start of the research. The authors are also very grateful to Dr João Rio and Mr Steve Ackerley for their invaluable help in devising and building the bender elements. The research was made possible through funding from the Engineering and Physical Sciences Research Council's (EPSRC's) Cooperation Awards in Science and Engineering (CASE) in collaboration with Ove Arup and Partners.

\section{REFERENCES}

Abbiss, C. P. (1981). Shear wave measurements of the elasticity of the ground. Géotechnique 31, No. 2, 94-104.

Al-Tabbaa, A. \& Wood, D. M. (1987). Some measurements of the permeability of kaolin. Géotechnique 37, No. 4, 499-503.

Anderson, D. G. \& Stokoe, II, K. H. (1978). Shear modulus: a time-dependent soil property. Dynamic Geotech. Testing, ASTM, STP 654, 66-90.

Atkinson, J. H., Richardson, D. \& Robinson, P. J. (1987). Compression and extension of $K_{0}$ normally consolidated kaolin clay. ASCE J. Geotech. Engng. 113, No. 12, 1468-1482.

Bishop, A. W. \& Wesley, L. D. (1975). A hydraulic triaxial apparatus for controlled stress path testing. Géotechnique 25, No. 4, 657-670.

Bjerrum, L. (1967). Engineering geology of Norwegian normallyconsolidated marine clays as related to settlements of buildings. In Milestones in soil mechanics, pp. 173-211. London: Thomas Telford Ltd.

Clayton, C. R. I. \& Heymann, G. (2001). Stiffness of geomaterials at very small strains. Géotechnique 51, No. 3, 245-255.

Clayton, C. R. I. \& Khatrush, S. A. (1986). A new device for measuring local axial strain on triaxial specimen. Géotechnique 36, No. 4, 593-597.

Cuccovillo, T. \& Coop, M. R. (1997). The measurement of local axial strains in traixial tests using LVDTs. Géotechnique 47, No. $1,167-171$.

de Freitas, M. H. \& Mannion, W. G. (2007). A biostratigraphy for the London Clay in London. Géotechnique 57, No. 1, 91-99.

Gasparre, A. (2005). Advanced laboratory investigation of London Clay. $\mathrm{PhD}$ thesis, Imperial College of Science Technology and Medicine, University of London.

Gasparre, A., Nishimura, S., Coop, M. R. \& Jardine, R. J. (2007a). The influence of structure on the behaviour of London Clay. Géotechnique 57, No. 1, 19-31.

Gasparre, A., Nishimura, S., Minh, N. A., Coop, M. R. \& Jardine, R. J. (2007b). The stiffness of natural London Clay. Géotechnique 57, No. 1, 33-48.

Greening, P. D., Nash, D. F. T., Benahmed, N., Ferreira, C. \& Viana da Fonseca, A. (2003). Comparison of shear wave velocity measurements in different materials using time and frequency domain techniques. Proc. 3rd Int. Symp. TC29: Deformation Characteristics of Geomaterials, Lyon, 3, 381-386.

Hight, D. W., Gasparre, A., Nishimura, S., Minh, N. A., Jardine, R. J. \& Coop, M. R. (2007). Characteristics of the London Clay from the Terminal 5 site at Heathrow Airport. Géotechnique 57, No. 1, 3-18.

Houlsby, G. T. \& Wroth, C. P. (1991). The variation of shear modulus of a clay with pressure and overconsolidation ratio. Soils Found. 18, No. 3, 138-143.

Jardine, R. J. (1992). Some observations on the kinematic nature of soil stiffness. Soils Found. 29, No. 3, 436-447.

Jardine, R. J. (1994). One perspective of the pre-failure deformation characteristics of some geomaterials. Proc. Int. Symp. Pre-Failure Deformation Characteristics of Geomaterials, Hokkaido 2, 855-885.

Jovicic, V., Coop, M. R. \& Simic, M. (1996). Objective criteria for determining $G_{\max }$ from bender element tests. Géotechnique 46, No. 2, 357-362.

Leroueil, S. \& Marques, M. E. S. (1996). Importance of strain rate and temperature effects in geotechnical engineering. ASCE Geotech. Special Publication 61, 1-60.

Lo Presti, D. C. F., Jamiolkowski, M., Pallara, O. \& Cavallaro, A. (1996). Rate and creep effect on the stiffness of soils. ASCE Geotech. Special Publication 61, 166-180.

Lohani, T. N., Imai, G., Tani, K. \& Shibuya, S. (2001). $G_{\max }$ of fine-grained soils at wide void ratio range, focussing on the time-dependent behavior. Soils Found. 41, No. 5, 87-102.

Mitchell, J. K. \& Soga, K. (1997). Fundamentals of soil behavior, 3rd edn. Chichester: John Wiley.

Rammah, K. I., Val, D. V. \& Puzrin, A. M. (2004). Effect of ageing on small-strain stiffness of overconsolidated clays. Géotechnique 54, No. 5, 319-322.

Shibuya, S. (2000). Assessing structure of aged natural sedimentary clays. Soils Found. 40, No. 3, 1-16.

Shibuya, S., Mitachi, T., Hosomi, A. \& Hwang, S. C. (1996). Strain rate effects on stress-strain behaviour of clay as observed in monotonic and cyclic triaxial tests. In Measuring and Modeling Time Dependent Soil Behaviour, Geotechnical Special Publication, ASCE Washington Convention '96, pp. 214-227. Lisse: Balkema.

Simpson, B. (1992). Retaining structures: displacement and design. Géotechnique 42, No. 4, 541-576.

Singh, A. \& Mitchell, J. K. (1968). General stress-strain-time function for soils. J. Soil Mech. Found. Div., ASCE 94, No. 1, $21-46$.

Soga, K. \& Mitchell, J. K. (1996). Rate-dependent deformation of structured natural clays. ASCE Geotech. Special Publication 61, 243-257.

Sorensen, K. K., Baudet, B. A. \& Simpson, B. (2007). Influence of structure on the time-dependent behaviour of a stiff sedimentary clay. 'Stiff sedimentary clays - Genesis and engineering behaviour'. Géotechnique 57, No. 1, 113-124.

Tatsuoka, F., Ishihara, M., Di Benedetto, H. \& Kuwano, R. (2002). Time-dependent shear deformation characteristics of geomaterials and their simulation. Soils Found. 42, No. 2, 103-129.

Viggiani, G. \& Atkinson, J. H. (1995). Stiffness of fine-grained soil at very small strains. Géotechnique 45, No. 2, 249-265. 